\title{
Biocontrol capability of local Metschnikowia sp. isolates
}

\author{
Ewelina Pawlikowska • Steve A. James • Emilia Breierova - Hubert Antolak (i) • \\ Dorota Kregiel (1)
}

Received: 7 February 2019/Accepted: 3 May 2019/Published online: 20 May 2019

(C) The Author(s) 2019

\begin{abstract}
This study set out to isolate and identify epiphytic yeasts producing pulcherrimin, and to evaluate their potential as biological control agents (BCAs). We isolated Metschnikowia sp. strains from flowers and fruits collected in Poland. The plant material had been collected between April to September 2017 from two small orchards where traditional organic management is employed. We identified the essential phenotypic features of the yeast, including assimilation and enzymatic profiles, stress resistance, adhesion properties, and antimicrobial activity against
\end{abstract}

E. Pawlikowska $(\bowtie) \cdot$ H. Antolak · D. Kregiel $(\square)$ Institute of Fermentation Technology and Microbiology, Lodz University of Technology, Wolczanska 171/173, 90-924 Lodz, Poland

e-mail: ewelina.pawlikowska@edu.p.lodz.pl

D. Kregiel

e-mail: dorota.kregiel@p.lodz.pl

H. Antolak

e-mail: hubert.antolak@p.lodz.pl

\section{S. A. James}

Gut Microbes and Health, Quadram Institute Bioscience, Colney Lane, Norwich Research Park,

Norwich NR4 7UA, UK

e-mail: steve.james@quadram.ac.uk

E. Breierova

Culture Collection of Yeasts (CCY), Institute of

Chemistry, Slovak Academy of Sciences, Dúbravskácesta

9, 84538 Bratislava, Slovakia

e-mail: emilia.breierova@savba.sk various fungi involved in crop and/or food spoilage. Yeast screening was performed using YPD agar supplemented with chloramphenicol and Fe(III) ions. Taxonomic classification was determined by sequence analysis of the D1/D2 domains of the large subunit rRNA gene. The isolates were identified as Metschnikowia andauensis and Metschnikowia sinensis. The yeast isolates were further characterized based on their enzymatic and assimilation profiles, as well as their growth under various stress conditions. In addition, the hydrophobicity and adhesive abilities of the Metschnikowia isolates were determined using a MATH test and luminometry. Their antagonistic action against molds representing typical crop spoiling microflora was also evaluated. The assimilation profiles of the wild isolates were similar to those displayed by collection strains of $M$. pulcherrima. However, some of the isolates displayed more beneficial phenotypic properties, especially good growth under stress conditions. Several of the epiphytes grew well over a wider range of temperatures $\left(8-30{ }^{\circ} \mathrm{C}\right)$ and $\mathrm{pH}$ levels (3-9), and additionally showed elevated tolerance to ethanol (8\%), glucose $(30 \%)$, and peroxides $(50 \mathrm{mM})$. The hydrophobicity and adhesion of the yeast cells were strain- and surface-dependent. The tested yeasts showed potential for use as BCAs, with some exhibiting strong antagonism against molds belonging to the genera Alternaria, Botrytis, Fusarium, Rhizopus, and Verticillium, as well as against yeasts isolated as food spoilage microbiota. 
Keywords Yeast - Metschnikowia - Screening · Stress · Adhesion · BCA

\section{Introduction}

Protection against losses caused by crop pests, plant diseases in particular, can play a critical role in improving food security worldwide. The protection of crops against plant diseases has an obvious role to play in the growing demand for food quality and quantity (Savary et al. 2012). Direct yield losses caused by plant pathogens reduce global agricultural productivity by between 20 and 50\% (Kwasiborski et al. 2014; Savary et al. 2012). Molds are the most common postharvest pathogens that affect fruits and vegetables. The prevention of these fungi, including mycotoxigenic species and strains, is considered a valid strategy to reduce the risks associated with fungal contamination of processed food and feed.

Chemical pesticides are typically used to prevent crop infections. The main purpose of conventional pesticide use is to minimize losses caused by crop diseases, and thus increase overall crop yields. It is believed that almost one third of all crops are treated with pesticides worldwide (Samsidar et al. 2018). Until recently, the use of synthetic pesticides for plant protection was thought to be fairly safe. However, nowadays the consensus has changed and it is widely recognized that the use of chemicals leads to three important issues, namely: (1) increased public concern regarding the contamination of plants with residues of synthetic fungicides and their effects on human health; (2) increased resistance of pathogens, and (3) environmental pollution (Abbey et al. 2018).

The European Food Safety Authority (EFSA) systematically performs acute dietary risk assessment for pesticide/food product combinations. Based on the latest scientific evidence, the EFSA has concluded that long-term dietary exposure to pesticides is unlikely to pose a health risk to consumers. Nevertheless, a number of non-approved substances have been found repeatedly in samples produced in the EU, which in some cases exceed the legal limits. Pesticides are also found occasionally in organic foods, which is not permitted for this type of product. For example, in the framework of the EU-coordinated control program (EUCP), 12,168 food samples were analyzed covering 165 pesticides in 11 food products. Although within the legally permitted levels, $46.0 \%$ of the samples were found to have quantifiable residues, while $0.9 \%$ of the samples were considered to be not compliant with the legal limits (EFSA 2018).

Currently, many companies whose activities have historically focused on the development and commercialization of chemical pesticides are now acquiring small companies that are already developing or have the potential to develop new microbe-based pesticides (Jensen et al. 2016). Beneficial microorganisms represent a large group of "good" agents which, due to their ability to interfere with the growth of plant pathogens and their positive effects on plants, are considered as potentially safe-to-use biopesticides (Glare et al. 2016; Le Cointe et al. 2016). The development of biopesticides has seen significant advances, primarily because of impressive progress in the isolation and characterization of novel strains of microorganisms which fulfill the main requirements for BCAs: strong inhibition of plant pathogens and the ability to be mass produced via cheap standard fermentation. However, although BCAs are now becoming more widely commercially available, they still constitute a small fraction of the total market for plant protection products (Regnault-Roger 2012). The main reason seems to be that biological control is viewed with caution and skepticism by many in the agricultural community. Biological control must be extremely efficient, in the range of 95-98\%. Currently, this poses a significant challenge, and such levels are difficult to achieve on a reliable basis. It is essential that mass-produced products retain the properties of the initial lab-grown cultures. The formulation must maintain its species purity and the microbial cells their genetic stability, cell viability, and attributes as colonizers on fruit surfaces, as well as other aspects of their mechanism of action. The process must be cost effective, rely on industrial by-products as nutrients, and fermentation must be completed within $24-48 \mathrm{~h}$. Therefore, it is critical to develop comprehensive knowledge of BCAs, including their antagonistic activities, growth under stress conditions, adherence to surfaces, as well as biofilm formation (Wisniewski et al. 2010). 
Epiphytic yeasts seem a promising alternative to synthetic pesticides (Sipiczki 2006; Sui et al. 2015). Such yeasts are particularly valuable biological material, due to the fact they constitute a natural microflora of plants. Yeast strains originating from plants in the natural environment are well adapted and resistant to various factors, such as temperature and $\mathrm{pH}$ level, as well as osmotic and oxidative stresses. Epiphytic yeasts represent the largest component of the microbial community and have therefore adapted successfully to various specific ecological niches. Currently, the most promising yeasts appear to belong to Metschnikowia pulcherrima, Trichosporon pullulans, Rhodotorula glutinis, Pichia membranifaciens, Issatchenkia orientalis, Candida spp., Cryptococcus laurentii and Pichia anomala (Hu et al. 2017; Sui et al. 2015; El-Tarabily and Sivasithamparam 2006). These species have been used effectively as BCAs against a wide range of plant pathogens (Türkel et al. 2014). Candida guilliermondii versus Aspergillus spp., $M$. pulcherrima versus $A$. niger, and Candida sake versus A. tubingensis are three examples of yeast species that reduce grape colonization by mold pathogens (Sarrocco and Vannacci 2018).

Yeast strains belonging to Metschnikowia sp. are of particular interest (Kántor et al. 2015; Liu et al. 2017; Sipiczki 2006; Sisti and Savini 2014). In addition to the classical ways of action (i.e. competition for nutrients and space) and stress tolerance, the unique modes of biocontrol action employed by these yeasts are secretion of pulcherriminic acid and the ability to complex with Fe ions. Moreover, Metschnikowia sp. is able to secrete extracellular lytic enzymes, such as chitinase and glucosidases, which contribute to overall antifungal effects (Banani et al. 2015; Fia et al. 2005; Parafati et al. 2015; Saravanakumar et al. 2008). In turn, their metabolite pulcherriminic acid forms a chelate complex with iron ions. Therefore, the antagonistic action of Metschnikowia sp. is principally based on the depletion of iron, which is necessary for the growth of pathogens. Sipiczki (2006) showed that the antibacterial and antifungal activity of $M$. pulcherrima depends on the binding of iron in the growth medium. Hence, $M$. pulcherrima strains that produce high amounts of pulcherrimin are of great interest as growth inhibitors against pathogenic microorganisms (Kántor et al. 2015).

The aim of this study was to isolate and identify epiphytic yeasts producing pulcherrimin, and to evaluate their potential as BCAs. Their essential phenotypic features were determined, including assimilation and enzymatic profiles, stress resistance, adhesion properties and antimicrobial activity against various fungi involved in crop and/or food spoilage.

\section{Materials and methods}

Plant material

Flowers and fruits were collected between April and September 2017 in the Lodz Region, Poland (latitude $51^{\circ} 46^{\prime} 36^{\prime \prime} \mathrm{N}$; longitude $19^{\circ} 27^{\prime} 17^{\prime \prime} \mathrm{E}$ ) from two small orchards where traditional organic management was
Table 1 Plant material used in the study

\begin{tabular}{|c|c|c|c|c|}
\hline \multirow{2}{*}{$\frac{\text { No. }}{1}$} & \multicolumn{2}{|c|}{ Plant material (variety) } & \multirow{2}{*}{$\begin{array}{l}\text { Systematic name } \\
\text { Malus domestica Borkh. }\end{array}$} & \multirow{2}{*}{$\frac{\text { Harvesting time }}{\text { September } 2017}$} \\
\hline & Fruits & $\begin{array}{l}\text { Apple } \\
\text { (Golden Delicious) }\end{array}$ & & \\
\hline 2 & & $\begin{array}{l}\text { Red grapes } \\
\text { (Alden) }\end{array}$ & Vitis vinifera $\mathrm{L}$. & September 2017 \\
\hline 3 & & $\begin{array}{l}\text { Raspberry } \\
\text { (Heritage) }\end{array}$ & Rubus idaeus L. & September 2017 \\
\hline 4 & & $\begin{array}{l}\text { Red currant } \\
\text { (Rosetta) }\end{array}$ & Ribes spicatum & July 2017 \\
\hline 5 & & $\begin{array}{l}\text { Strawberry } \\
\text { (Senga Sengana) }\end{array}$ & Fragaria $\times$ ananassa & May 2017 \\
\hline 6 & Flowers & Strawberry & Fragaria $\times$ ananassa & July 2017 \\
\hline
\end{tabular}


employed (Table 1). The samples were collected aseptically using sterile gloves and plastic bags and immediately stored for several hours in a refrigerator. All the samples were then processed.

\section{Collection strains of Metschnikowia pulcherrima}

Five collections strains of Metschnikowia pulcherrima were used as reference material. Two strains of $M$. pulcherrima, NCYC747 and NCYC2321, were obtained from the National Collection of Yeast Cultures (Norwich, United Kingdom), while three strains, CCY 29-2-145, CCY 29-2-147, and CCY 29-2-149, were received from the Culture Collection of Yeasts (Bratislava, Slovakia). The strains were revived from stocks and sub-cultured on potato dextrose agar (PDA) slants $[4 \mathrm{~g} / \mathrm{L}$ potato infusion, $20 \mathrm{~g} / \mathrm{L}$ glucose, $15 \mathrm{~g} / \mathrm{L}$ agar] (Merck Millipore, Darmstadt, Germany) at $25^{\circ} \mathrm{C}$ for 3 days. The yeast cultures were stored on YPD agar slants (Merck Millipore, Darmstadt, Germany) at $4{ }^{\circ} \mathrm{C}$.

Fungal strains

To evaluate the antagonistic activities of the yeast isolates, five mold strains originating from the Culture Collection of Microorganisms LOCK105 (Lodz, Poland) were used: Alternaria alternata LOCK409, Botrytis cinerea LOCK453, Penicillium expansum (syn. P. glaucum) LOCK535, Rhizopus oryzae LOCK547, and Verticillium cinnabarinum LOCK576. The molds were stored on YPD agar slants (Merck Millipore, Darmstadt, Germany) at $4{ }^{\circ} \mathrm{C}$. They were preliminarily tested for pathogenicity on strawberry fruits. In addition, the wine strain Saccharomyces cerevisiae Tokay (LOCK203), yeasts Wickerhamomyces anomalus C1 (NCYC D5299), and Dekkera bruxellensis C2 (NCYC D5300), isolated from spoiled soft drinks in Poland, were used as test material (Kregiel et al. 2018).

Screening of pulcherrimin-producing yeasts

A $10 \mathrm{~g}$ sample of fruit material was gently homogenized in $90 \mathrm{~mL}$ of sterile distilled water and incubated for $5 \mathrm{~h}$ at room temperature $\left(20-22{ }^{\circ} \mathrm{C}\right)$. In the case of flowers, 10-15 inflorescences were processed. A
$100 \mu \mathrm{L}$ aliquot of each resulting homogenate was spread onto YGC agar plates supplemented with $0.05 \%(w / v) \mathrm{FeCl}_{3}$ solution [5 g/L yeast extract, $20 \mathrm{~g} /$ $\mathrm{L}$ glucose, $0.1 \mathrm{~g} / \mathrm{L}$ chloramphenicol, $20 \mathrm{~g} / \mathrm{L}$ agar] (Merck Millipore, Darmstadt, Germany) and incubated at $25{ }^{\circ} \mathrm{C}$ for 3 days. From each sample, 10 typical dark red or brown coloured colonies were selected randomly. For the isolation of pure cultures, the spread plate method and YGC agar with $0.05 \%$ $\mathrm{FeCl}_{3}$ were used to obtain pure cultures of yeasts producing pulcherrimin. The incubation conditions were the same as those used for the screening procedure. The pure yeast cultures were stored on YPD agar slants (Merck Millipore, Darmstadt, Germany) at $4{ }^{\circ} \mathrm{C}$.

\section{Identification of yeast isolates}

Species identification of all wild yeast isolates was performed by the National Collection of Yeast Cultures (Norwich, United Kingdom) by sequencing the D1/D2 variable domains of the larger RNA subunit gene (LSU). The variable D1 and D2 domains of the LSU rRNA gene were PCR-amplified as a single DNA fragment directly from whole yeast cell suspensions, following the procedure and PCR parameters described by Kregiel et al. (2018). The yeast LSU D1/D2 domain was amplified and sequenced using the conserved fungal primers NL1 (GCATATCAATAAGCGGAGGAAAAG) and NL4 (GGTCCGT GTTTCAAGACGG) (O'Donnell 1993). The amplified LSU D1/D2 products were separated using $1.0 \%$ agarose electrophoresis, then purified and concentrated using QIAquick PCR purification spin columns (QIAGEN) according to the manufacturer's instructions. A NanoDrop 1000 Spectrophotometer (Thermo Scientific) was used to measure the DNA concentration, and the samples were sequenced by a commercial sequencing facility (Eurofins MWG Operon). Sequence traces were edited manually, and consensus sequences were generated using the program SEQMAN, version 11 (DNASTAR). The LSU D1/D2 sequence of each yeast strain was compared with sequences held in the EMBL/GenBank sequence databases. The sequences were deposited in the GenBank database with assigned accession numbers. The yeast isolates have been deposited in the Culture 
Collection of Microorganisms LOCK105 (Lodz, Poland, WFCC No. 598, WDCM No. 105).

Yeast cultivation and testing

In order to assess the morphological features of the yeast isolates, they were cultivated in YPD broth (Merck Millipore, Darmstadt, Germany) for 2 days on a Heidolph Titramax 1000 rotary shaker (Heidolph, Schwabach, Germany) at $125 \mathrm{rpm}$. Pulcherrimin production was evaluated in YPD broth with $0.05 \%$ $\mathrm{FeCl}_{3}$. The yeast cells and pulcherrimin were observed using an OLYMPUS BX41 light microscope (Olympus, Shinjuku, Tokio, Japan) connected to a DP72 digital camera. In order to determine growth profiles under varying environmental conditions, including temperature $\left(2-55^{\circ} \mathrm{C}\right), \quad \mathrm{pH} \quad(2-9), \quad$ peroxide $(0-50 \mathrm{mM})$, glucose $(0.5-30 \% \mathrm{w} / \mathrm{v})$, and ethanol concentration $(1-8 \% \mathrm{w} / \mathrm{v})$, YPD medium was also used. Inoculation of the culture media was carried out using standardized suspensions of the tested yeasts $\left[\sim 1^{\circ} \mathrm{McF}\right]$. The intensity of yeast growth was measured using a DEN-1densitometer (Grant Instruments, Cambridge, UK) and expressed on the McFarland scale $\left[{ }^{\circ} \mathrm{McF}\right]$.

\section{Assimilation profiles}

The assimilation profile of each yeast isolate was determined using the API $20 \mathrm{C}$ AUX identification system (BioMérieux, Lyon, France), following the manufacturer's instructions. The resulting assimilation profiles for the wild isolates were compared to those determined previously for collection M. pulcherrima strains.

\section{Enzymatic fingerprinting}

The enzymatic profiles of the yeast isolates were determined using the API ZYM test (BioMérieux, Lyon, France). Inoculation and evaluation were carried out based on the manufacturer's instructions and recommendations. The profiles of the isolates were compared to those obtained for collection M. pulcherrima strains.
Adhesion abilities

White glass slides $(\mathrm{G})$ were used as the reference hydrophilic material $(76 \times 26 \mathrm{~mm}$, Star Frost, Knittel Glass, Braunschweig, Germany) and polypropylene (PP) as the reference hydrophobic surface (76 × $26 \mathrm{~mm}$, Paccor Packaging, Skierniewice, Poland). The values for the contact angles of the reference materials were determined as $44.2 \pm 4.3^{\circ}$ and $92 \pm 4.7^{\circ}$, respectively (Antolak et al. 2018).

The minimal culture medium $\left[3 \mathrm{~g} / \mathrm{L}\left(\mathrm{NH}_{4}\right)_{2} \mathrm{SO}_{4}\right.$, $1 \mathrm{~g} / \mathrm{L} \quad \mathrm{KH}_{2} \mathrm{PO}_{4}, 1 \mathrm{~g} / \mathrm{L} \quad \mathrm{K}_{2} \mathrm{HPO}_{4}, \quad 0.5 \mathrm{~g} / \mathrm{L} \quad \mathrm{MgSO}_{4}$ $\times 7 \mathrm{H}_{2} \mathrm{O}, 1 \mathrm{~g} / \mathrm{L}$ yeast extract, $10 \mathrm{~g} / \mathrm{L}$ glucose] was sterilized at $121{ }^{\circ} \mathrm{C}$. Into $50 \mathrm{~mL}$ Erlenmeyer flasks was poured $25 \mathrm{~mL}$ of the medium, into which sterile glass carriers were placed vertically in such a way that part of the carrier was immersed while the rest was outside the liquid. The inoculum was standardized to obtain a cell concentration in the culture medium of approximately $10^{2}-10^{3} \mathrm{CFU} / \mathrm{mL}$ at the beginning of the experiment. The samples were incubated at $25^{\circ} \mathrm{C}$ on a laboratory shaker (125 rpm) for 7 days.

Cell adhesion to the carriers was analyzed by luminometry and scanning electron microscopy (SEM). For luminometric tests, the carrier was removed from the culture medium, rinsed with sterile distilled water and swabbed using free-ATP sampling pens (Merck Millipore, Darmstadt, Germany). The measurements were reported in relative light units per square centimeter $\left(\mathrm{RLU} / \mathrm{cm}^{3}\right)$ using a HY-LiTE ${ }^{\circledR} 2$ luminometer (Merck Millipore, Darmstadt, Germany) (Kregiel 2013b). For SEM studies, a Jeol JSH 5500 LV microscope was used in high vacuum mode at an accelerating voltage of $10 \mathrm{kV}$. The samples were coated with a fine layer of gold (approximately $20 \mathrm{~nm}$ thick) using an ion-coating JEOL JFC 1200 apparatus (Fortuniak et al. 2018).

\section{Hydrophobicity}

The ability of yeast cells to adhere to hydrocarbons was determined as a measure of their hydrophobicity (MATH test), according to the method described by Kregiel (2013a). Planktonic yeast cells were cultivated in the minimal medium and harvested by 
centrifugation at $5000 \mathrm{rpm}$ for $5 \mathrm{~min}$ at $4{ }^{\circ} \mathrm{C}$. They were then washed twice in PBS and finally resuspended in the same buffer. The cell suspensions were adjusted to an $\mathrm{A}_{0}$ value of approximately 5.0 at $540 \mathrm{~nm}$ (Spekol 220, Zeiss, Germany), before $2 \mathrm{~mL}$ of the yeast suspensions were added to $0.4 \mathrm{~mL}$ of xylene (OBR PR, Poland) and vortexed for $60 \mathrm{~s}$. The two phases were allowed to separate for $10 \mathrm{~min}$ at $25^{\circ} \mathrm{C}$. The aqueous phase was removed carefully and the A value at $540 \mathrm{~nm}$ was measured once more. A decrease in the absorbance of the aqueous phase was taken as a measure of cell surface hydrophobicity $(\mathrm{H})$, calculated using the following formula: $\mathrm{H}=\left[\left(\mathrm{A}_{0}-\mathrm{A}\right)\right.$ / $\left.\mathrm{A}_{0}\right] \times 100 \%$, where $\mathrm{A}_{0}$ and $\mathrm{A}$ are the absorbance before and after extraction with xylene, respectively. The yeast cells were classified in terms of their percentage affinity to xylene using the following scale: $<10 \%$ hydrophilic, 10-29\% medium hydrophilic, $30-55 \%$ medium hydrophobic, $>55 \%$ highly hydrophobic.

\section{Antagonism in vitro}

The antagonistic effects of the yeast isolates against spore germination and the hyphal growth of different mold species were tested using the cross method with some modifications (Balouiri et al. 2016). A loopful of spores from fully sporulated mold strains was collected aseptically and resuspended in $1 \mathrm{~mL}$ of sterile saline. The obtained spore suspensions $\left(\sim 10^{6} \times \mathrm{mL}^{-1}, 100 \mu \mathrm{L}\right)$ were spread evenly on the YPD agar plates. Then yeast cell suspensions ( $\left.\sim 10^{7} \times \mathrm{mL}^{-1}, 2 \mu \mathrm{L}\right)$ were dropped on the plates in duplicate, and the plates were incubated at $25{ }^{\circ} \mathrm{C}$ for 7 days. Inhibition zones were measured $(\mathrm{mm})$ at the end of the incubation period. All experiments on the antagonistic effects of yeast strains were performed in triplicate.

Efficacy: preliminary studies on soft fruits

Fresh strawberries, harvested in a Polish orchard and grown according to organic management practices, were washed in sterile saline $(0.85 \% \mathrm{w} / \mathrm{v})$ and drained at room temperature. Each fruit portion $(\sim 5 \mathrm{~g})$ was exposed to spray treatment with $2 \mathrm{~mL}$ of a yeast suspension $\left(\sim 10^{7}\right.$ cells $\left.\times \mathrm{mL}^{-1}\right)$ of a Metschnikowia sp. strain. After $1 \mathrm{~h}, 2 \mathrm{~mL}$ of a spore suspension of grey mold $B$. cinerea $\left(\sim 10^{6}\right.$ spores $\left.\times \mathrm{mL}^{-1}\right)$ was pipetted onto the fruit. An inoculated control was also performed using $2 \mathrm{~mL}$ of conidial suspension. The fruits were packed randomly in commercial plastic boxes and stored at $10{ }^{\circ} \mathrm{C}$ for 3 weeks. A trained panel of 10 individuals was used to evaluate their sensorial properties before and after storage. The samples after washing with tap water were assessed in terms of color and flavor. Each attribute was scored on the following 3-point hedonic scale: $1=$ acceptable; $2=$ perceptibly altered but still acceptable; $3=$ unacceptable. The taste, odor, and color typical of the fruits, as exemplified by frozen samples that had been thawed prior to the sensory evaluation, were regarded as acceptable. All experiments were performed in duplicate (Nowak et al. 2016).

\section{Statistics}

The mean results taken from three independent experiments were calculated. Comparisons between the mean values were performed using the One-Way ANOVA test (STATISTICA 10, TIBCO Software Inc., Palo Alto, CA, USA) followed by a Tukey's multiple comparison test. Assimilation and enzymatic profiles were obtained from API $20 \mathrm{C}$ AUX and API ZYM tests results (BioMérieux, Lyon, France). Assimilation tests and enzymatic fingerprinting were visualized by hierarchical clustering using ClustVis (https://biit.cs.ut.ee/clustvis/), a web tool for presenting multivariate data. Other yeast profiles were created with Plotly (https://plot.ly/\#/), a free web tool for data visualization (Antolak et al. 2018, 2019).

\section{Results and discussion}

Screening and identification

The yeast screening method we employed, using YGC agar supplemented with $\mathrm{Fe}$ (III) ions, allowed us to obtain characteristic brown or red colonies (Fig. 1a- 

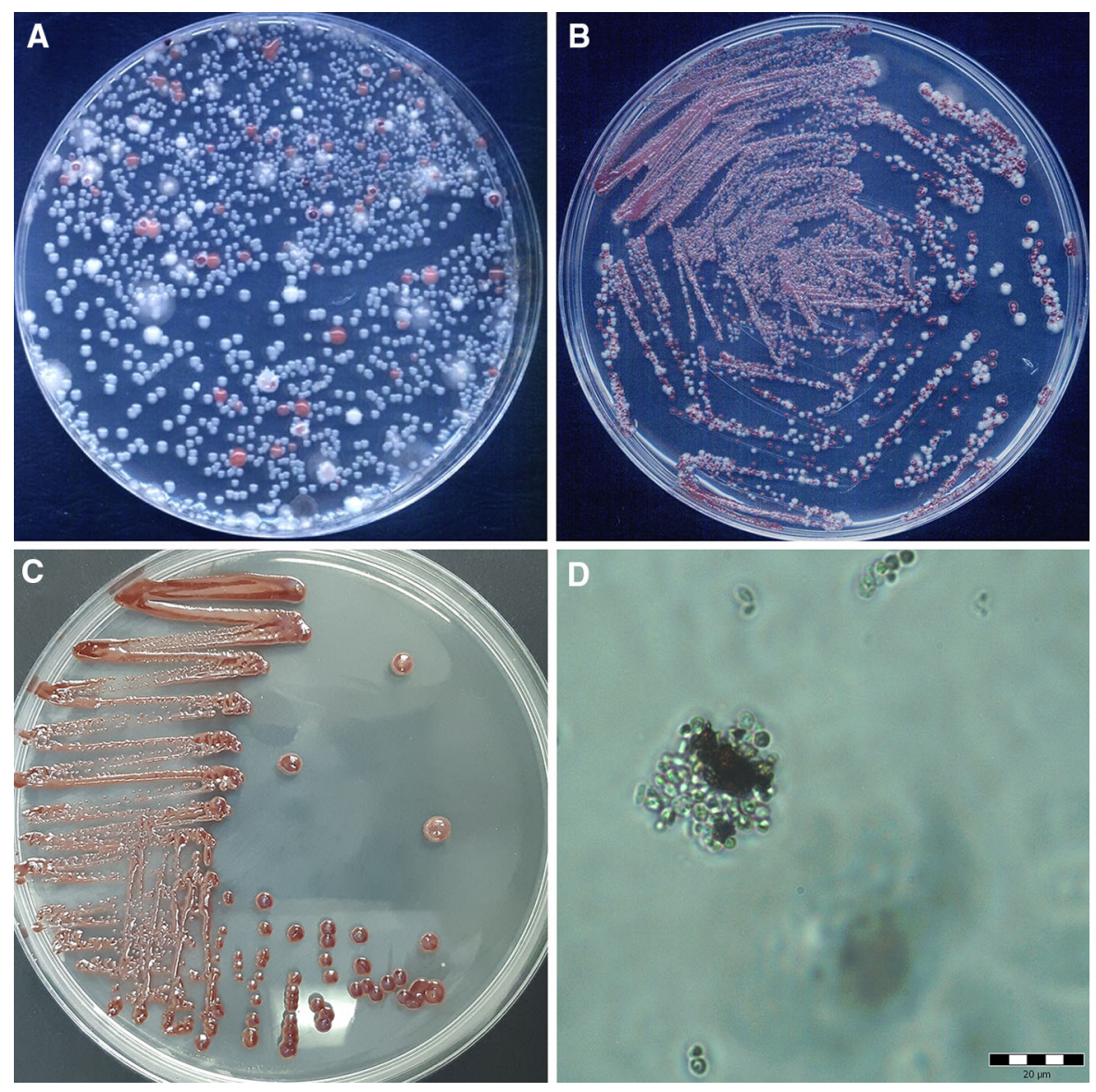

Fig. 1 Screening (a) and isolation (b, c) of yeasts on YGC agar medium with Fe(III). d Yeast cells harvested from YPD broth with $\mathrm{Fe}(\mathrm{III})$ visible using a light microscope

c). From the total plant material, 48 characteristic clones were isolated, and from these the 10 yeast isolates that had formed the darkest colonies (labelled D1 to D10) were selected for further studies. The streak plate procedure was conducted several times on YPD agar to ensure that each isolate was a monoculture. Microscopic observations were made to determine the morphology of each monoculture (Fig. 1d). The isolate cell size typically ranged from 2 to $12 \mu \mathrm{m}$ in length and from 2 to $10 \mu \mathrm{m}$ in width. All the yeast isolates were reproduced vegetatively by budding, with some cells forming groups while others remained separate. In yeast cultures obtained from YPD broth with added Fe(III) ions, visible amorphous red inclusions accumulated in both the cells and the growth medium. This standard procedure for recovering Metschnikowia sp. isolates based on pulcherrimin formation has been used in numerous studies (Kántor et al. 2015; Oro et al. 2014; Pretscher et al. 2018; Sipiczki 2006; Türkel and Ener 2009). It is welldocumented that the antimicrobial activity of $M$. pulcherrima strains depends on pulcherrimin pigment production, which in turn inhibits the growth of sensitive microorganisms by iron sequestration (Sipiczki 2006). The yeast isolates that produced large amounts of pulcherrimin and thus grew as dark brown colonies in the presence of $\mathrm{Fe}(\mathrm{III})$ ions were therefore selected, since they were of the greatest interest as potential inhibitors of pathogenic microorganisms. 
Table 2 Results of molecular identification of yeast isolates

\begin{tabular}{|c|c|c|c|c|c|}
\hline No. & Strain symbol & Origin & & Species & GenBank accession number \\
\hline 1 & D1 & Fruits & Apple & M. sinensis & MK612094 \\
\hline 2 & D2 & & & M. andauensis & MK612095 \\
\hline 3 & D3 & & Raspberry & M. sinensis & MK612096 \\
\hline 4 & D4 & & & M. andauensis & MK612097 \\
\hline 5 & D5 & & Grape & M. andauensis & MK612098 \\
\hline 6 & D6 & & & M. andauensis & MK612099 \\
\hline 7 & D7 & & Red currant & M. andauensis & MK612100 \\
\hline 8 & D8 & & & M. andauensis & MK612101 \\
\hline 9 & D9 & & Strawberry & M. sinensis & MK612102 \\
\hline 10 & D10 & Flower & Strawberry & M. sinensis & MK612103 \\
\hline
\end{tabular}

All the yeast isolates were identified by ribosomal DNA (rDNA) sequencing. Each yeast monoculture was identified to species level by sequencing the D1/ D2 domains of the large subunit rRNA gene. The 10 selected yeast isolates (D1-D10) were taxonomically classified as either Metschnikowia andauensis or Metschnikowia sinensis (Table 2). A similar identification procedure is used by the NCYC Collection for various yeasts. This methodology has also been applied to identify Wickerhamomyces spp., Candida spp., Kazachstania spp. and Dekkera spp. isolates (James et al. 2013, 2014, 2015; Kregiel et al. 2018). However, it is worth noting that each isolate displayed a notable level of sequence variation in comparison to the respective species type strain. Modern yeast taxonomy is based on phylogenetic analysis of conserved DNA regions or protein sequences. By far the most frequently used sequences are those of the D1 and D2 domains of the large subunit (LSU, 26S) rDNA. Most researchers opt to use this DNA marker for species identification of yeast, because the rDNA repeats within an individual genome generally have identical sequences (due to sequence homogenization). However, in a recent study Sipiczki et al. (2013) discovered that the rDNA arrays of certain Metschnikowia strains were in fact not fully homogenized. While seemingly rare, rDNA heterogeneity has been observed in yeasts, perhaps most notably in Saccharomyces cerevisiae (James et al. 2009) and most recently in Kluyveromyces marxianus (Perpetuini et al. 2018).
Previous studies of ascomycetous yeasts have revealed that strains displaying more than $1 \%$ sequence variation in the D1/D2 domains usually belong to separate species (Kurtzman and Robnett 1998). The intragenomic D1/D2 sequence diversity of Metschnikowia sp. strains D1-D10 exceeded this intraspecies diversity. Phylogenetic analysis of the 26S rDNA D1/D2 domain sequence showed that $M$. andauensis and $M$. sinensis are clustered in a clade together with M. fructicola, M. pulcherrima and M. chrysoperlae (Xue et al. 2006). Kurtzman and coworkers hypothesize that hybridization contributes to the intragenomic diversity of Metschnikowia (Kurtzman et al. 2018). This phenomenon has been demonstrated experimentally by Sipiczki and co-workers (Sipiczki et al. 2018). Thus, the intra-strain sequence variation we observed in our isolates may indicate that they possess rDNA arrays of hybrid origin, i.e. rDNA from two parental Metschnikowia sp. A possible explanation for the observed intra-strain (intragenomic) sequence variation observed in isolates D1D10 may therefore be intraspecies and/or interspecies hybridizations. Recently, significant divergences have been reported in strains belonging to Clavispora lusitaniae and Metschnikowia bowlesiae (Lachance and Fedor 2014; Durrens et al. 2017).

Sipiczki et al. (2018) found a high degree of sequence diversity in the D1/D2 domains of two pulcherrimin-producing Metschnikowia species. The sequences of the internal transcribed spacers (ITS) were also not homogenized and differed from each 
Fig. 2 Assimilation profiles. Hierarchical clustering of positive/ negative results. Distance measure: Euclidean. Clustering algorithm: Ward. Each row represents an individual strain, while each column represents a carbon source

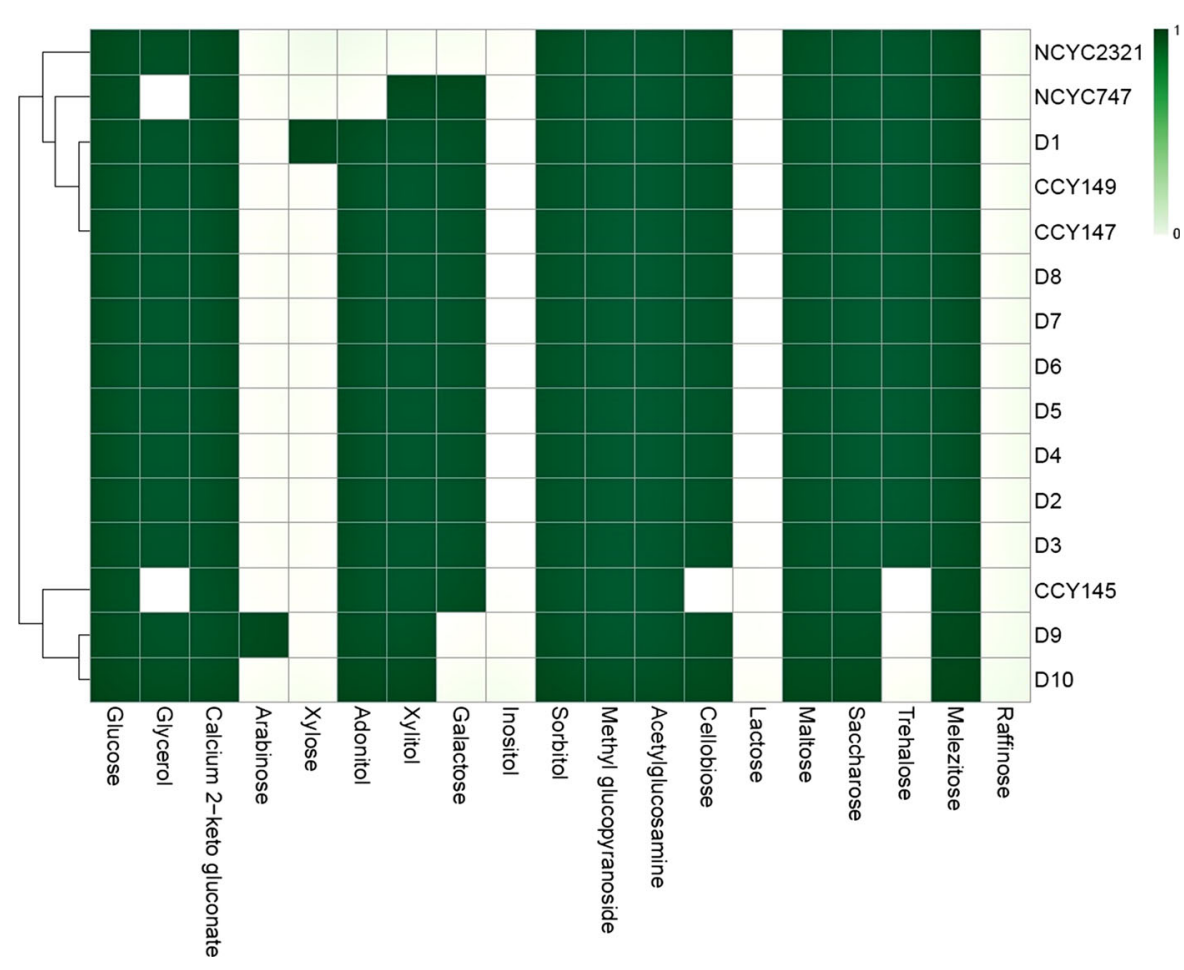

other. This high intragenomic diversity makes the D1/ D2 domains and the ITS spacers unsuitable for barcoding. Therefore, the taxonomic position of the strains previously assigned to them requires revision. Because of this peculiarity of pulcherrimin-producing Metschnikowia strains, precise taxonomic identification is practically impossible. To emphasize this fact, the present study uses symbols for strains D1-D10 belonging to Metschnikowia sp.

\section{Assimilation profiles}

Of the carbon compounds used to characterize yeasts, two sugars, sucrose and L-sorbose, are usually utilized by most Metschnikowia sp., whereas the assimilation of inulin, raffinose, lactose, starch, rhamnose, L- and D-arabinose, methanol, erythritol, galactitol, inositol, and glucuronic acid is rather rare. Other carbon compounds, such as $\beta$-glucosides, ethanol, glycerol, mannitol, glucitol, succinic and 2-ketogluconic acids, and $\mathrm{N}$-acetylglucosamine may also be assimilated, but there is variation between strains (Lachance et al.
2016). All the tested yeasts assimilated all the carbon sources except raffinose, lactose, and inositol (Fig. 2). However, strong differences were noticeable between the collection strains and the set of isolates used in our study. For example, isolates D1 and D9 are able to assimilate xylose and arabinose, respectively. Narrow assimilation profiles were observed in the collection strains M. pulcherrima NCYC2321 and NCYC747, but the broadest profile was seen for isolate D1. The use of the ClustVis program allowed us to group the tested yeast strains into three main clusters: the first and third clusters contained both collection strains and epiphytes with very diverse profiles, while the second cluster was composed of isolates D2 to D8, which had the same assimilation profile.

\section{Enzymatic fingerprinting}

The enzyme systems for fungal cell lysis are usually a mixture of several different enzymes, including one or more $\beta-1,3-$ and $\beta-1,6$-glucanases, proteases, mannanases, and chitinases, all acting synergistically to 
Fig. 3 Enzymatic fingerprinting. Hierarchical clustering of positive (1-5) and negative $(0)$ results. Distance measure: Euclidean. Clustering algorithm: Ward. Each row represents an individual strain, while each column represents an enzyme. (For interpretation of the references to color in this figure legend, the reader is referred to the web version of this article). (Color figure online)

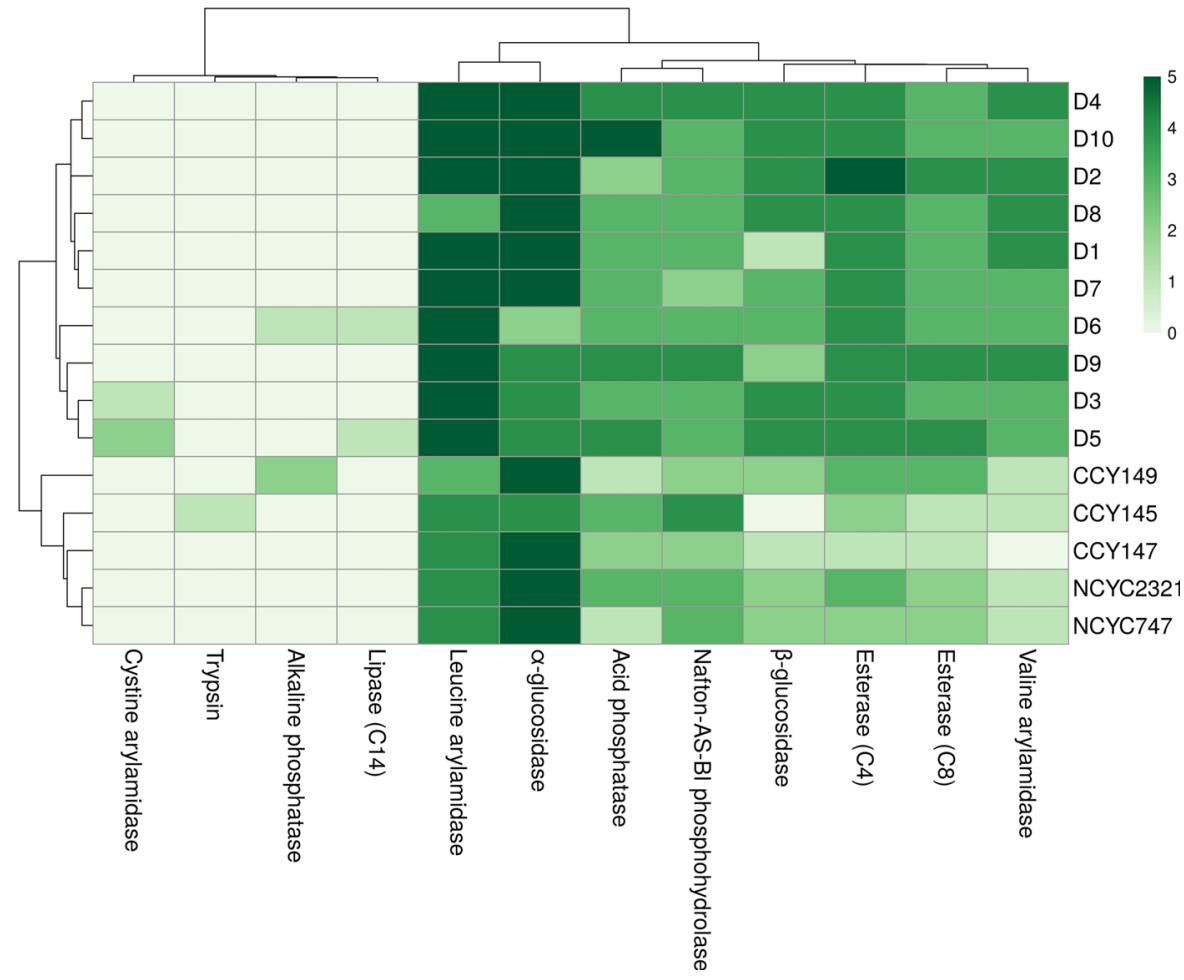

lyse the cell wall. It is worth noting that the activity of one group of enzymes may influence that of the second. For example, $\alpha$ - and $\beta$-glucosidase activities may stimulate the action of $\alpha$ - and $\beta$-glucanases on cell-wall components (Banani et al. 2015; Pretscher et al. 2018). Enzymatic profiles obtained from the API ZYM system indicate that all the tested strains showed $\alpha$-glucosidase and leucine arylamidase activities (Fig. 3). The results for $\alpha$-chymotrypsin, $\alpha$-galactosidase, $\beta$-galactosidase, $\beta$-glucuronidase, $\mathrm{N}$-acetyl- $\beta$ glucosaminidase, $\alpha$-mannosidase, and $\alpha$-fucosidase were either negative or very weak for all the tested strains. They were therefore excluded from the comparative analysis of Metschnikowia strains. In general, a distinct difference was observed between the collection strains and isolates D1-D10. The epiphytic yeasts showed higher enzymatic activities for esterases, valine arylamidase, acid phosphatase, $\beta$ glucosidase and naphtol-AS-BI-phosphohydrolase.

The use of hierarchical clustering allowed us to group the yeast strains into 3 main clusters. The first contained all the collection strains, the second comprised isolates D3, D5, D6, and D9, while the third contained epiphytes D1, D2, D4, D7, D8, and D10, which displayed the strongest enzymatic activity. The wide spectrum of enzymatic action may also play an important role in biocontrol mechanisms. The hydrolytic activity of yeasts can play an important role in both their colonization and invasion (Staniszewska et al. 2013). It is worth noting the activity of leucine arylamidase in all the tested strains. This enzyme is a member of the metalo-peptidase group, which removes the N-terminal L-leucine from peptide substrates. Leucine arylamidase activity provides leucine molecules needed for the formation of pulcherrimine acid, and finally pulcherrimin (Kántor et al. 2015; Sipiczki 2006).

Stress resistance

Microorganisms found in natural environments and under industrial conditions are exposed to high 
A
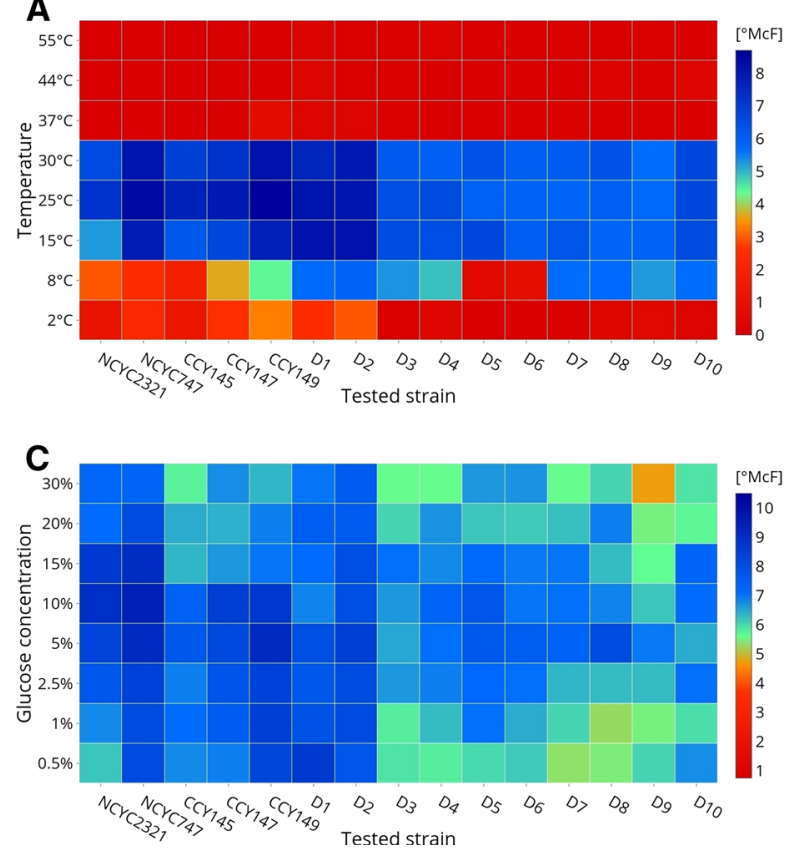

Fig. 4 Growth profiles under stress conditions. Each row represents a tested parameter, while each column represents a tested strain. The blue color corresponds to the highest values,

fluctuations, caused by variable weather conditions as well as crop storage methods. Thus, to be successful biological control agents antagonists need to show effective mechanisms to cope with the plethora of abiotic stresses to which they will be exposed. Further studies are necessary on the effects of numerous environmental factors on potential BCA, especially to assess the viability of yeast antagonists (Sui et al. 2015).

Figure 4a presents temperature profiles for the growth of the tested yeast strains in culture media incubated over a wide range of temperatures, from 2 to $55^{\circ} \mathrm{C}$. All of the tested strains were able to grow at between 8 and $30{ }^{\circ} \mathrm{C}$, but the best growth was recorded at temperatures between 15 and $30{ }^{\circ} \mathrm{C}$. According to Lachance et al. (2016), growth at the elevated temperature of $37{ }^{\circ} \mathrm{C}$ is characteristic for species belonging to the M. lunata clade. However, isolates from tropical climate may show good growth at higher
B
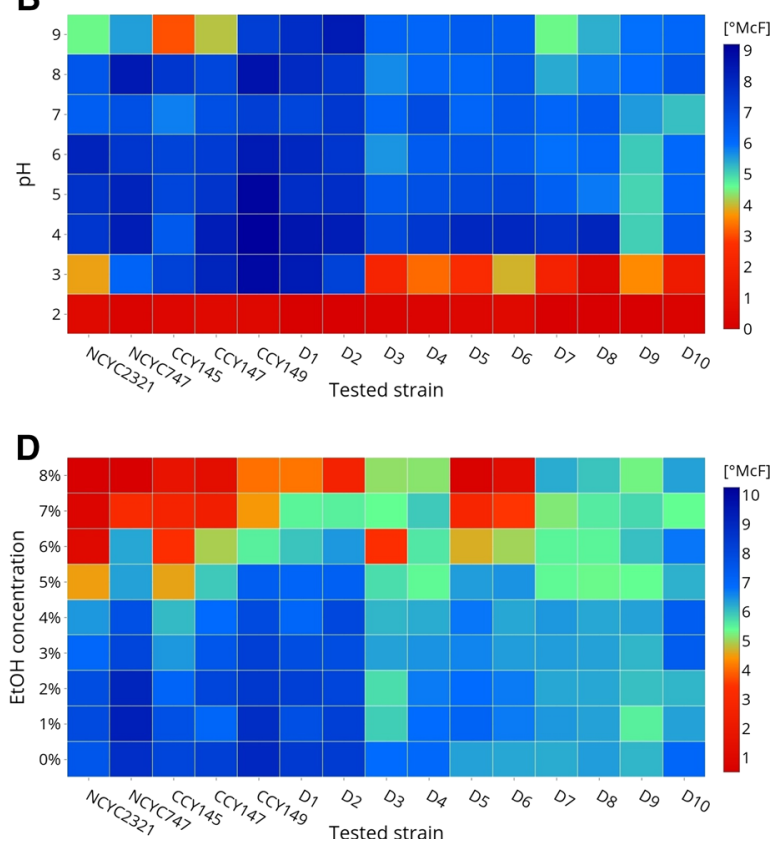

while the red color corresponds to the lowest. (For interpretation of the references to color in this figure legend, the reader is referred to the web version of this article). (Color figure online)

temperatures. For example, an epiphytic isolate of $M$. persimmonesis collected in South Korea was found to be able to grow at $40{ }^{\circ} \mathrm{C}$ (Kang et al. 2017). Furthermore, it is possible to improve the thermal resistance of some yeast strains. For example, in studies by Liu et al. (2011), mild heat shock pretreatment at $40{ }^{\circ} \mathrm{C}$ was found to improve the heat tolerance of $M$. fructicola, resulting in it being able to grow at $45{ }^{\circ} \mathrm{C}$.

In the present study, the $M$. pulcherrima collection strains NCYC747, CCY 29-2-147, and CCY 29-2149 , as well as isolates D1 and D2, were all able to grow at $2{ }^{\circ} \mathrm{C}$. Vegetables and fruits are usually stored at low temperatures, in order to extend their commercial shelf life and availability. Therefore, the ability of yeasts to colonize and develop on a host (the commodity) at low temperatures is an important biocontrol feature (Sangorrín et al. 2014; Sui et al. 2015). 
Fig. 5 Growth in the presence of peroxides $\left(\mathrm{H}_{2} \mathrm{O}_{2}\right)$. Each row represents a tested parameter, while each column represents a tested strain. The blue color corresponds to the highest values, while the red color corresponds to the lowest. (For interpretation of the references to color in this figure legend, the reader is referred to the web version of this article). (Color figure online)

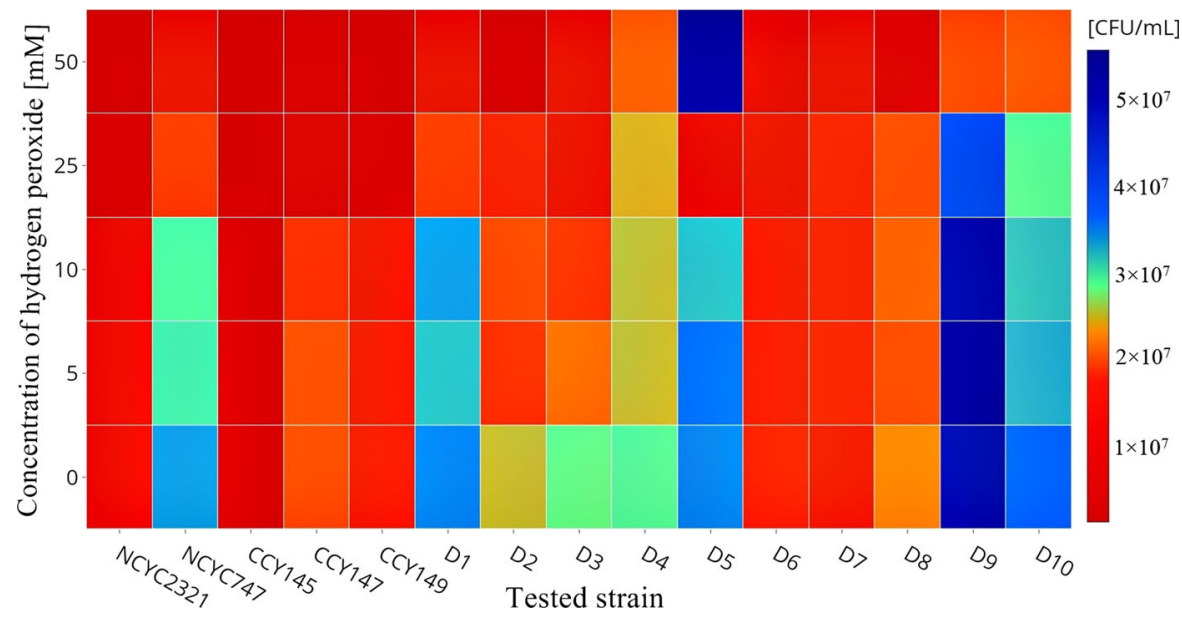

Figure $4 \mathrm{~b}$ shows the results of yeast growth in culture medium with different $\mathrm{pH}$ values, ranging from 2 to 9 . All the tested strains were characterized by the ability to grow over a broad range of $\mathrm{pH}$, from 3 to 9. The most significant yeast growth occurred when the $\mathrm{pH}$ values of the medium ranged from 4 to 8 . Similar results were obtained in a previous study for M. pulcherrima (Spadaro et al. 2010), whereas a strain of M. persimmonesis isolated from Korean persimmon showed higher optimal pH 6 (Kang et al. 2017). Good growth at $\mathrm{pH} 3$ was particularly evident for collection strains NCYC747, CCY 29-2-145, CCY 29-2-147, and CCY 29-2-149, as well as two epiphytes isolated from apples (D1 and D2). According to the literature, stress-adapted yeasts growing well at $\mathrm{pH} 4$ can effectively inhibit apple rots caused by the mold $P$. expansum (Liu et al. 2012). As in the case of temperature stress, it is also possible to improve the resistance of yeasts to low $\mathrm{pH}$. Wang et al. (2014) noted that low $\mathrm{pH}$ tolerance in the basidiomycetous yeast Rhodosporidium paludigenum may be improved by incubation in media with $\mathrm{pH}$ levels ranging from 4.0 to 5.5. This pretreatment resulted in a higher growth rate on apples and thus greater biocontrol efficacy.

The ability to withstand osmotic stress (dehydration, freezing, and osmotic agents) is another trait that can make yeasts suitable for use as BCAs (Sui et al.
2015). Figure $4 c$ shows the growth of yeasts in the presence of glucose at concentrations ranging from 0.5 to $30 \%(w / v)$. Despite the fact that all the tested strains were characterized by relatively high osmotic tolerance, two collection strains (NCYC2321 and NCYC747) as well as some isolates (e.g. D1, D2) showed a greater ability to withstand osmotic stress in comparison to the other strains tested. Osmotolerance — growth in the presence of 50\% glucose—varies widely in Metschnikowia sp. (Lachance et al. 2016). As microbial growth at high sugar concentration is advantageous for biocontrol activity, yeasts isolated from high-osmotic environments may also be a good source of new BCAs (Liu et al. 2013).

Figure $4 \mathrm{~d}$ shows the ethanol tolerance of the tested yeast strains. The results indicate that all the tested strains showed growth in the presence of $5 \%(\mathrm{v} / \mathrm{v})$ ethanol. However, many of our isolates were able to grow in the presence of $8 \%(v / v)$ alcohol. Yeasts belonging to $M$. pulcherrima with low fermentation capacity (about $4 \% \mathrm{v} / \mathrm{v}$ ) have been described as also having rather low ethanol tolerance $(3-6 \% \quad v / v)$ (Aponte and Blaiotta 2016; Lachance et al. 2016). However, in a study conducted by Barbosa et al. (2018), some M. pulcherrima strains were found to be able to tolerate up to $9 \% v / v$ ethanol. This confirms the results of our studies. Ethanol tolerance may be important feature of BCAs in wine-making. Molds are 
Fig. 6 Hydrophobic properties of yeast cells harvested from two culture media: a YPD broth, b minimal medium

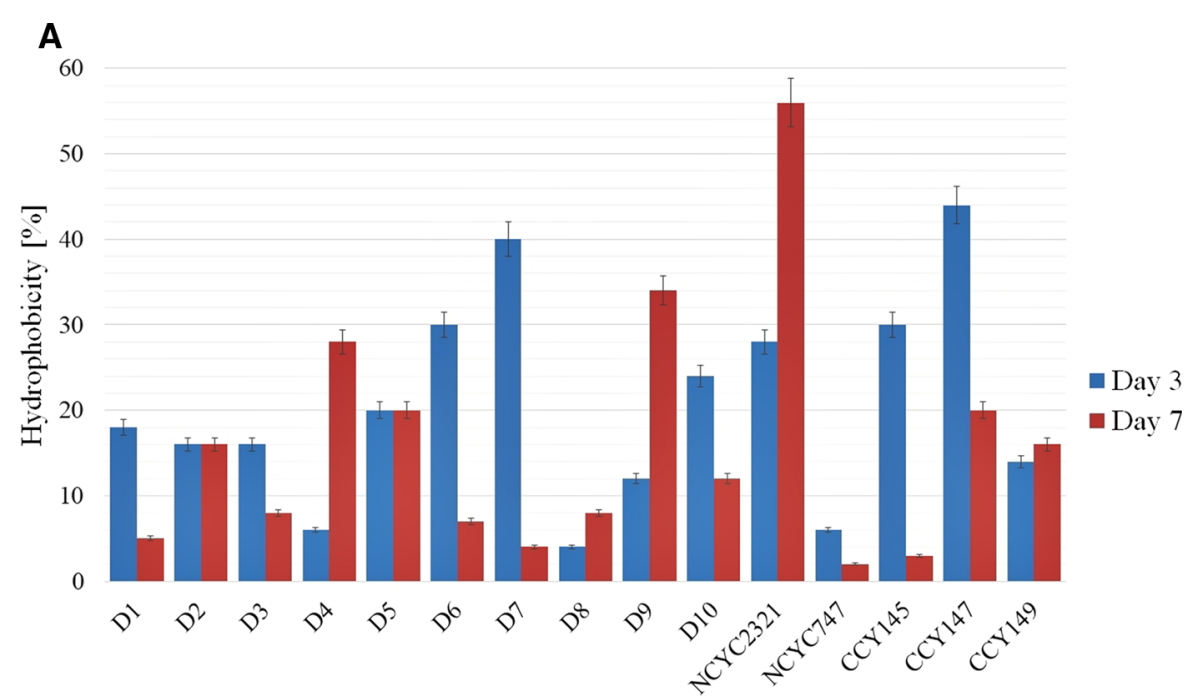

Tested strain

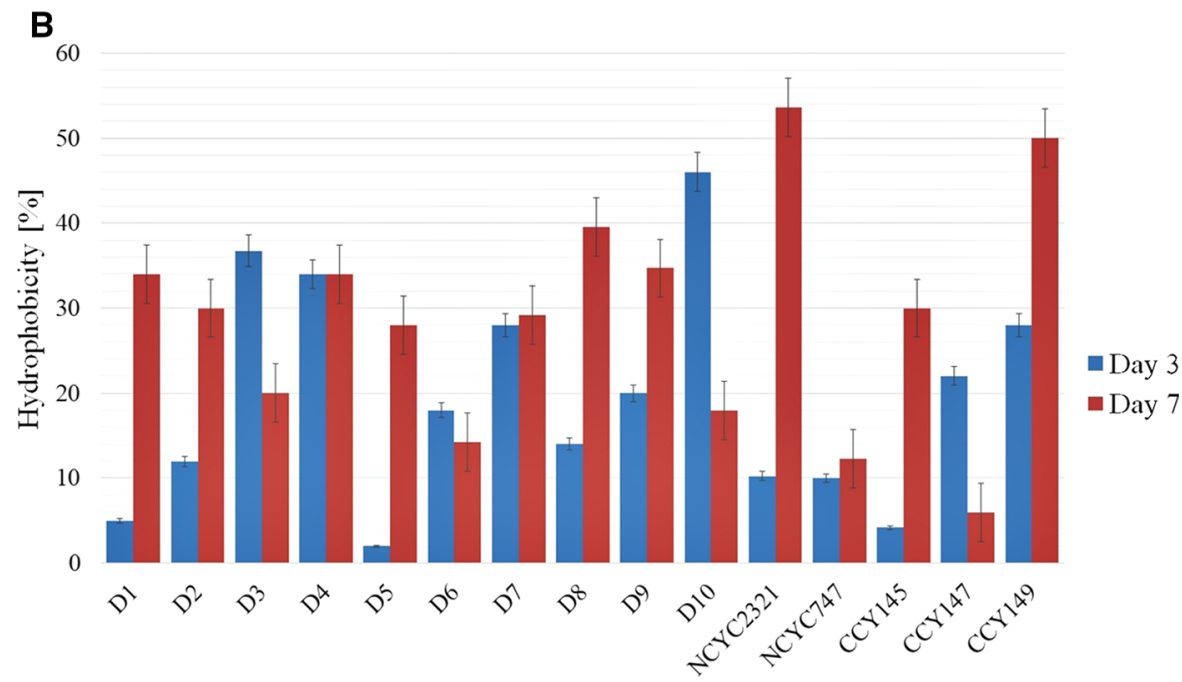

Tested strain unable to grow in wine, but their effect on wine quality is due to grape damage and the production of specific metabolites in the early stages of fermentation. The selection and use of 'autochthonous yeasts' as biocontrol agents in early fermentation may assist the prevention of fungal spoilage (Mills et al. 2002).

It has been suggested that reactive oxygen species (ROS) signalling is a component in the mode of action of yeast antagonists in biocontrol systems (Chi et al. 2015). Antagonistic yeasts may serve as elicitors, triggering ROS signalling in host tissue and leading to the activation of host defences (Sui et al. 2015). This postulate is supported by studies analysing the molecular basis of yeast-fruit interactions. Biocontrol agents must be able to tolerate ROS-derived oxidative stress, which can affect their viability and efficacy. 
Fig. 7 Cell adhesion to glass and polypropylene surfaces (RLU/cm²)

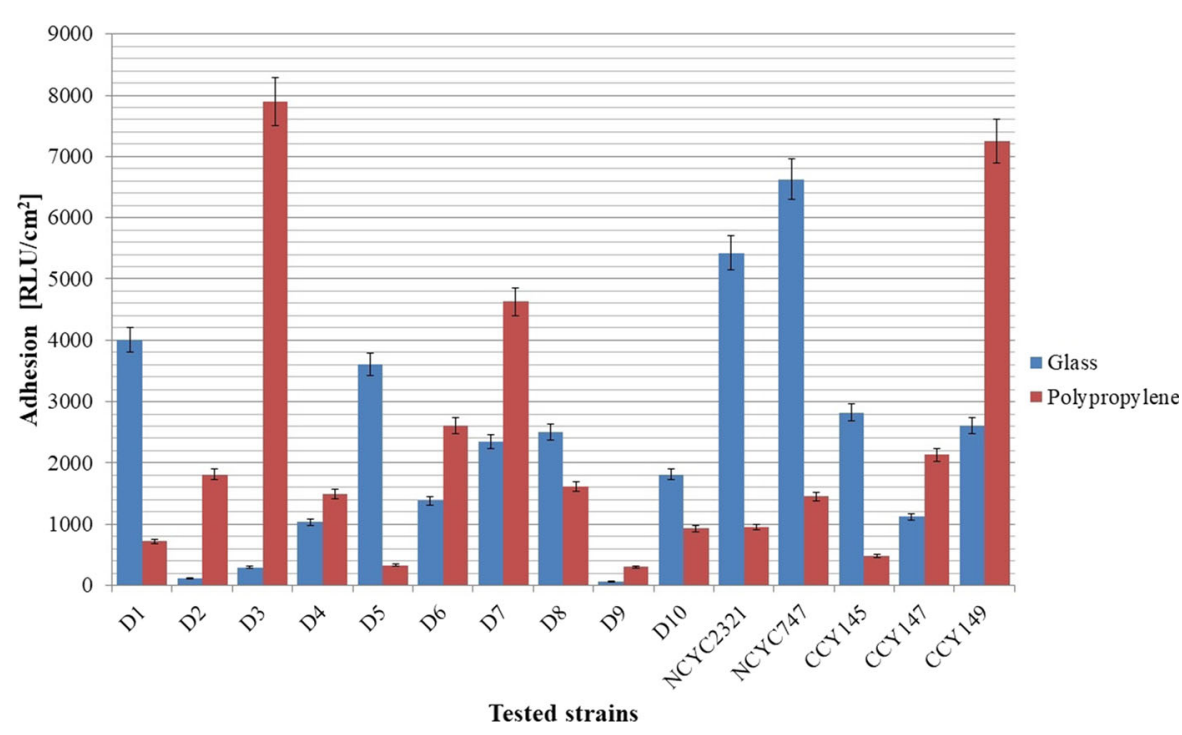

Yeasts with higher resistance to ROS-generated oxidative stress exhibit greater colonization and better biocontrol efficacy (Castoria et al. 2003). Liu et al. (2011) examined the responses of strains belonging to Metschnikowia sp. to oxidative stress. They found that $M$. fructicola was the most tolerant species, surviving well in $200 \mathrm{mM} \mathrm{H}_{2} \mathrm{O}_{2}$. Li et al. (2014) report that the survival of Pichia caribbica decreased significantly as the concentration of $\mathrm{H}_{2} \mathrm{O}_{2}$ was increased from 5 to $20 \mathrm{mM}$. Figure 5 shows the growth of the tested strains of Metschnikowia sp. in different concentrations of $\mathrm{H}_{2} \mathrm{O}_{2}$. The controls were samples without the addition of peroxide. In general, the isolates showed greater resistance to hydrogen peroxide, especially strains D4, D5, D9, and D10, which survived at a level of $2 \times 10^{7} \mathrm{CFU} / \mathrm{mL}$ in the presence of $50 \mathrm{mM} / \mathrm{mL}$ $\mathrm{H}_{2} \mathrm{O}_{2}$. On the other hand, the greatest sensitivity to the test compound was shown by collection strains NCYC2321, CCY 29-2-145, and CCY 29-2-147, as well as by isolates D2 and D8.

\section{Hydrophobicity and adhesion abilities}

The ability to form biofilms is as an effective mechanism of action for some BCAs. One of the most important factors is the initial attachment of biofilm, since cell adhesion is a necessary first step in biofilm formation (Liu et al. 2014). In the natural environment, crop surfaces are frequently wetted by rainfall, dewfall, fog, or cloud mist. Therefore, the special hydrophobicity/hydrophilicity of BCA cells may contribute to better adhesion properties to the surface of crops and reduce the overall leaching of yeast cells (Abdel-Kader et al. 2012; Krasowska and Sigler 2014).

We studied the hydrophobic properties of yeast cells harvested from two differed culture media: minimal medium and rich YPD broth. In general, the yeast cells harvested from the rich culture medium showed more hydrophilic properties (Fig. 6a) than those grown in the minimal medium (Fig. 6b). The only exceptions were the strain NCYC2321, which displayed hydrophobicity in both culture media, and strain CCY29-2-147, which showed hydrophilic properties in the minimal medium. Similar results were obtained by Rodríguez et al. (2018), who noted that the M. pulcherrima strain showed rather hydrophilic properties.

Over millions of years of evolution, plants have developed a wide diversity of surfaces adapted to their 

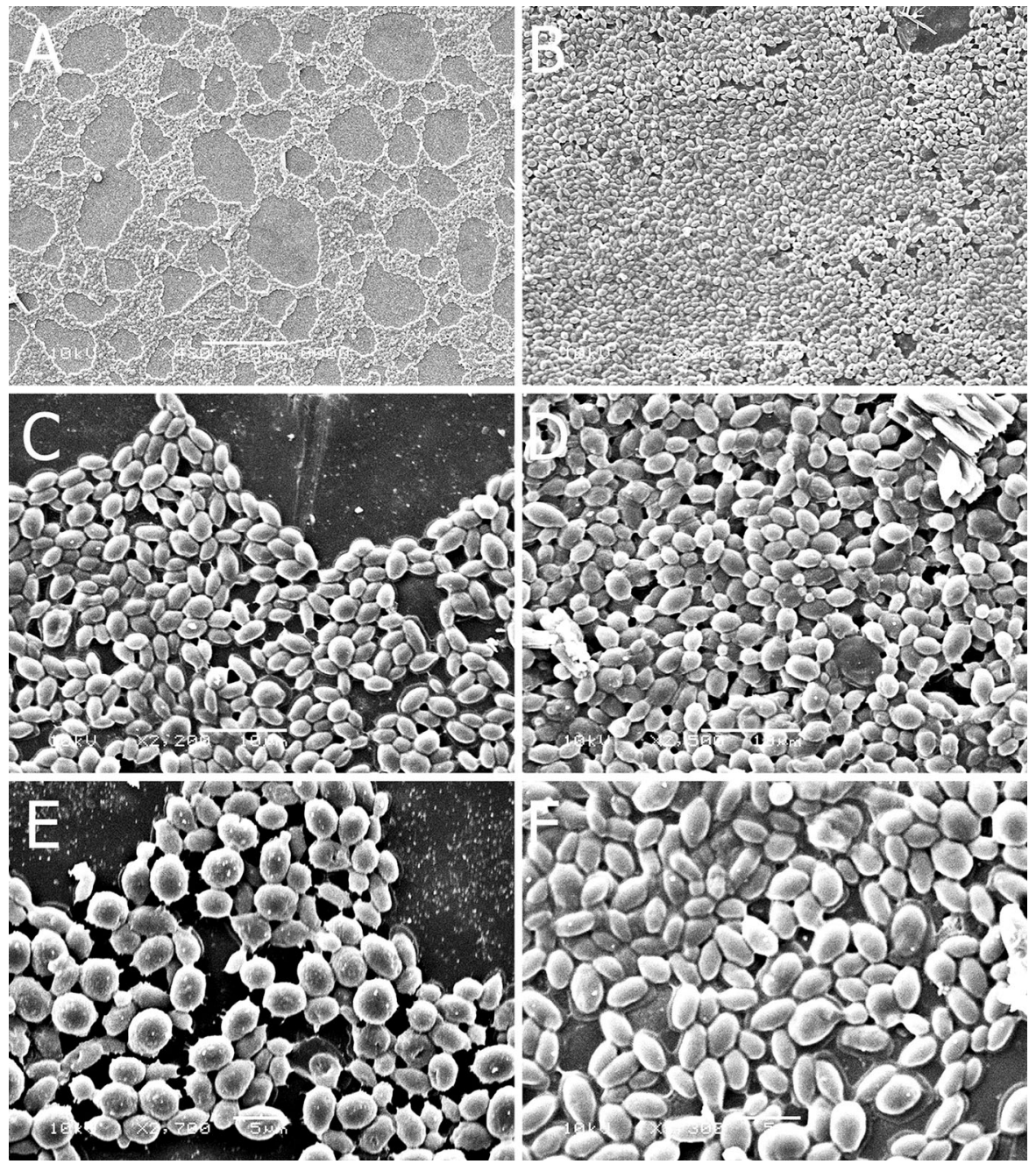

Fig. 8 Cell adhesion to the glass and polyethylene surfaces observed in SEM

specific environments. The structural basis of hydrophobic and hydrophilic plant surfaces is variable. It may be based on smooth surfaces, but also surface structuring, such as water-absorbing hairs, porous and sponge-like structures, or rough convex surface structures. In this study, we used well-defined abiotic carriers. Yeast cell adhesion to two types of substrate, namely glass (hydrophilic) and polypropylene (hydrophobic), was analyzed by luminometry and scanning electron microscopy. According to the literature, luminometry is an efficient and reliable way to determine microbial attachment to surfaces (Kregiel 2013b). The approach is based on bacterial
ATP quantification, and can be applied to detect not only adhered cells, but also their extracellular secretions. Figure 7 presents the results of yeast adhesion to a glass surface $\left(\mathrm{RLU} / \mathrm{cm}^{2}\right)$ in minimal medium, where most strains displayed higher level of hydrophobicity. The levels of cell adhesion to glass and polypropylene varied, ranging from 70 to $6600 \mathrm{RLU} / \mathrm{cm}^{2}$ and from 250 to $7900 \mathrm{RLU} / \mathrm{cm}^{2}$, respectively. The luminometric results were both strain and surface dependent. Slightly higher results were obtained for the plastic surface and for half of the strains tested, regardless of their origin. 


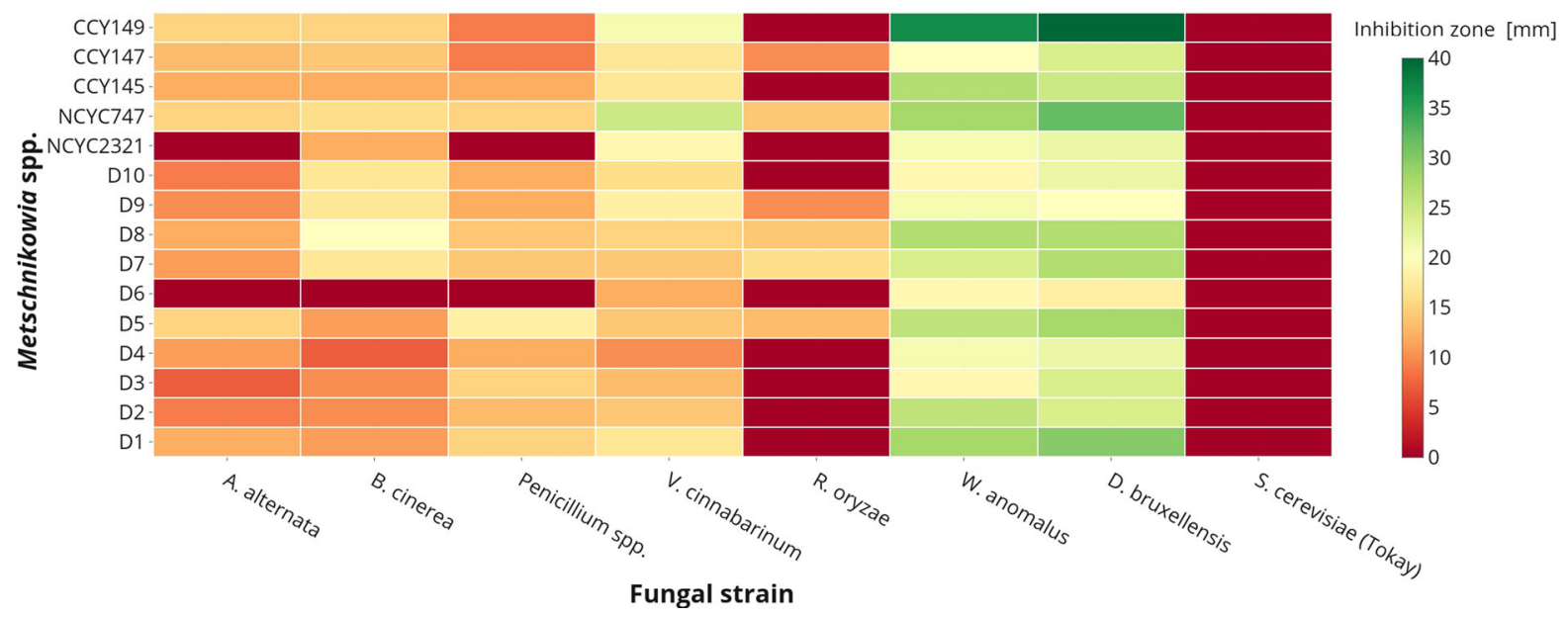

Fig. 9 Antagonism of Metschnikowia sp. strains. Each row represents the tested Metschnikowia strain, while each column represents a tested fungal microorganism. The green color corresponds to the highest values in the inhibition zone, while

A qualitative analysis of cell adhesion was also conducted, based on SEM. Figure 8 shows images of the glass (Fig. 8a, c, e) and polypropylene (Fig. 8b, d, f) after 5-day incubation with isolate D3 in minimal medium. In general, microscopic observations confirmed the luminometric results. The best adhesion was observed on the hydrophobic plastic material, resulting in surface coverage of approximately $80-90 \%$ of the total area. In addition, it was observed under high magnification that the attached yeast cells were covered with an extracellular substance which could also be detected luminometrically (Fig. 8e, f). The good adhesion of the tested strains of Metschnikowia sp. to both hydrophobic and hydrophilic surfaces suggests that they may be able to colonize plant surfaces effectively. This feature reinforces the conclusion that Metschnikowia sp. is a promising source of BCA.

\section{Antagonism in vitro}

Figure 9 presents the inhibitory activity of the Metschnikowia strains against 5 pathogenic mold strains. The tested yeast strains inhibited various fungal pathogens. However, the halo of inhibition was the red color corresponds to lack of inhibition. (For interpretation of the references to color in this figure legend, the reader is referred to the web version of this article). (Color figure online)

strain-dependent. Inhibition has also been observed for the yeasts $W$. anomalus and D. bruxellensis, which are often isolated as spoilage microbiota in foods and beverages (Kregiel et al. 2018), although not for the $S$. cerevisiae Tokay wine strain. It is worth noting that $W$. anomalus has likewise been suggested as a possible biocontrol yeast (Kurtzman 2011; Zhang et al. 2019).

It has been reported that iron sequestration inhibits conidial germination and hyphae growth, by inducing autolysis at the hyphal tips (Sipiczki 2006). Moreover, mutants that do not form pulcherrimin also lack antifungal activity. Therefore, in Metschnikowia yeast the contribution of other factors (e.g. wall lytic enzymes) to antifungal activity seems to be very minor compared to that of iron complexing.

\section{Efficacy on soft fruits}

The influence of Metschnikowia sp. strains on the organoleptic qualities of strawberries was evaluated after treatment with a Botrytis cinerea conidial suspension. Of the numerous pathogens that cause fruit diseases in strawberries, the gray mold $B$. cinereal is the most widespread globally. In addition, this mold is known for its innate resistance to 
Table 3 Sensory analysis of strawberry fruits stored at $8{ }^{\circ} \mathrm{C}$

\begin{tabular}{|c|c|c|c|}
\hline Storage time (weeks) & Yeast strain & Color & Flavor \\
\hline \multirow[t]{16}{*}{0} & NCYC2321 & $1.0 \pm 0.0$ & $1.0 \pm 0.0$ \\
\hline & NCYC747 & $1.0 \pm 0.0$ & $1.0 \pm 0.0$ \\
\hline & CCY145 & $1.0 \pm 0.0$ & $1.0 \pm 0.0$ \\
\hline & CCY147 & $1.0 \pm 0.0$ & $1.0 \pm 0.0$ \\
\hline & CCY149 & $1.0 \pm 0.0$ & $1.0 \pm 0.0$ \\
\hline & D1 & $1.0 \pm 0.0$ & $1.0 \pm 0.0$ \\
\hline & D2 & $1.0 \pm 0.0$ & $1.0 \pm 0.0$ \\
\hline & D3 & $1.0 \pm 0.0$ & $1.0 \pm 0.0$ \\
\hline & D4 & $1.0 \pm 0.0$ & $1.0 \pm 0.0$ \\
\hline & D5 & $1.0 \pm 0.0$ & $1.0 \pm 0.0$ \\
\hline & D6 & $1.0 \pm 0.0$ & $1.0 \pm 0.0$ \\
\hline & D7 & $1.0 \pm 0.0$ & $1.0 \pm 0.0$ \\
\hline & D8 & $1.0 \pm 0.0$ & $1.0 \pm 0.0$ \\
\hline & D9 & $1.0 \pm 0.0$ & $1.0 \pm 0.0$ \\
\hline & D10 & $1.0 \pm 0.0$ & $1.0 \pm 0.0$ \\
\hline & Control & $1.0 \pm 0.0$ & $1.0 \pm 0.0$ \\
\hline \multirow[t]{16}{*}{3} & NCYC2321 & $1.3 \pm 0.1$ & $1.0 \pm 0.0$ \\
\hline & NCYC747 & $1.6 \pm 0.1$ & $1.0 \pm 0.0$ \\
\hline & CCY145 & $1.5 \pm 0.1$ & $1.0 \pm 0.0$ \\
\hline & CCY147 & $1.0 \pm 0.0$ & $1.0 \pm 0.0$ \\
\hline & CCY149 & $1.6 \pm 0.2$ & $1.0 \pm 0.0$ \\
\hline & D1 & $1.2 \pm 0.1$ & $1.0 \pm 0.0$ \\
\hline & D2 & $1.0 \pm 0.0$ & $1.4 \pm 0.2$ \\
\hline & D3 & $1.4 \pm 0.3$ & $1.0 \pm 0.0$ \\
\hline & D4 & $1.3 \pm 0.3$ & $1.0 \pm 0.0$ \\
\hline & D5 & $1.3 \pm 0.2$ & $1.0 \pm 0.0$ \\
\hline & D6 & $1.4 \pm 0.3$ & $1.2 \pm 0.2$ \\
\hline & D7 & $1.3 \pm 0.1$ & $1.0 \pm 0.0$ \\
\hline & D8 & $1.2 \pm 0.3$ & $1.3 \pm 0.2$ \\
\hline & D9 & $1.3 \pm 0.1$ & $1.0 \pm 0.0$ \\
\hline & D10 & $1.2 \pm 0.3$ & $1.0 \pm 0.0$ \\
\hline & Control & $3.0 \pm 0.0$ & $3.0 \pm 0.0$ \\
\hline
\end{tabular}

Hedonic scale: 1 = acceptable; 2 = perceptibly altered but still acceptable; 3 = unacceptable

Quantitative variables are expressed as means and standard deviations. "-" not evaluated

fungicides, which is due to its high genetic variability, profuse production of spores, and multiple cycles of spore production and disease development (Koike and Bolda 2016). Therefore, this fungal pathogen was
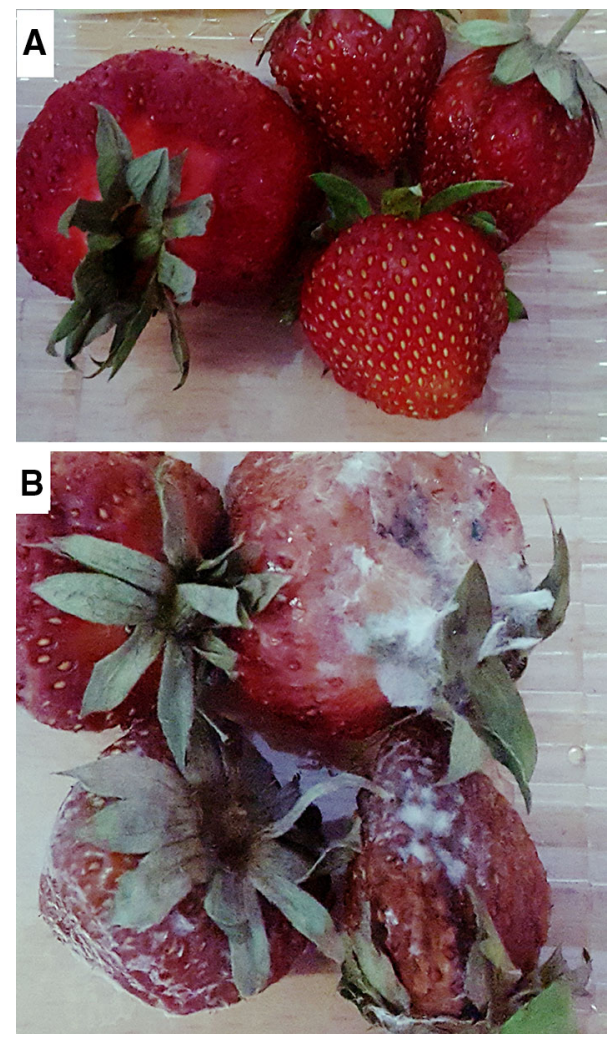

Fig. 10 Strawberry fruits after 3 -week storage at $8{ }^{\circ} \mathrm{C}$. a Fruits treated by grey mold and isolate D2; b fruits treated with grey mold (control sample)

selected for use in our preliminary studies. The addition of yeast suspensions did not have any negative effect on the sensory attributes of the strawberries. Initially, all the tested fruits were acceptable. After 3 weeks of refrigerated storage, the control samples treated with $B$. cinerea showed a loss of organoleptic quality, and the growth of grey mold was also visible. In contrast, all the other strawberry samples treated with both $B$. cinerea and isolate D2 remained visually acceptable after a 3 -week period of storage at $8{ }^{\circ} \mathrm{C}$ (Table 3, Fig. 10a). Control samples (contaminated by mold, without the addition of yeast cells) obtained a score of 3.0 (Fig. 10b). It is worth noting that the fruit surfaces treated with Metschnikowia sp. took on a characteristic intense red color, and the flavor either remained specific or an additional pleasant floral aroma was perceptible. 


\section{Conclusions}

This study forms part of research aimed at identifying new effective BASs for large-scale applications. It is worth noting that commercialized biofungicides containing yeast strains $M$. fruticola have already been developed, such as the bioproduct "Shemer" (AgroNews 2010). Formal EU approval has been granted to yeast-based biofungicides using $M$ fructicola strain NRRL Y-27328, following a favorable vote by EU member states (Commission Implementing Regulation (EU) 2018/1915). The Metschnikowia isolates tested in our study show promising features as potential BCAs. They inhibited common fungi, widespread in the world as plant pathogens and causative agents of food spoilage. They were characterized by various phenotypical properties, and most grew well under stressful conditions, as did the culture collection strains. The isolates showed a slightly wider assimilation spectrum than the collection strains. However, for effective implementation under field conditions, the use of BCAs requires an integrative approach, including additional practices that can decrease the incidence or severity of disease. These methods may include appropriate crop rotation and management of crop residues, the application of organic amendments and the use of new technologies, such as the biological disinfestation of soils.

Authors' contributions EP and DK: Conception and design of the work. SAJ, EB, HA, and EP: Data collection. EP, SAJ, and DK: Data analysis and interpretation. EP and DK: Drafting the article.

\section{Compliance with ethical standards}

Conflict of interest The authors declare that they have no conflict of interest.

Ethical approval This article does not contain any studies with human participants and/or animals performed by any of the authors.

Open Access This article is distributed under the terms of the Creative Commons Attribution 4.0 International License (http:// creativecommons.org/licenses/by/4.0/), which permits unrestricted use, distribution, and reproduction in any medium, provided you give appropriate credit to the original author(s) and the source, provide a link to the Creative Commons license, and indicate if changes were made.

\section{References}

Abbey JA, Percival D, Abbey L, Asiedu SK, Prithiviraj B, Schilder A (2018) Biofungicides as alternative to synthetic fungicide control of grey mould (Botrytis cinerea) - prospects and challenges. Biocontrol Sci Technol. https://doi. org/10.1080/09583157.2018.1548574

Abdel-Kader MM, El-Mougy NS, Lashin MDA (2012) Different approaches of bio-control agents for controlling root rot incidence of some vegetables under greenhouse conditions. Int J Agric Biol 2(1):115-117. https://doi.org/10.5923/j. ijaf.20120201.18

AgroNews (2010) Bayer CropScience acquires biofungicide from AgroGreen. http://news.agropages.com/News/ NewsDetail-2142.htm. Accessed 12 Feb 2019

Antolak H, Czyzowska A, Kregiel D (2018) Activity of Mentha piperita $\mathrm{L}$. ethanol extract against acetic acid bacteria Asaia spp. Foods 7(10):171. https://doi.org/10.3390/ foods 7100171

Antolak H, Jelen H, Otlewska A, Kregiel D (2019) Volatile compounds associated with growth of Asaia bogorensis and Asaia lannensis - unusual spoilage bacteria of functional beverages. Food Res Int 121:379-386. https://doi. org/10.1016/j.foodres.2019.03.054

Aponte M, Blaiotta G (2016) Potential role of yeast strains isolated from grapes in the production of taurasi DOCG. Front Microbiol 7:809. https://doi.org/10.3389/fmicb. 2016.00809

Balouiri M, Sadiki M, Ibnsouda SK (2016) Methods for in vitro evaluating antimicrobial activity: a review. J Pharm Anal 6(2):71-79. https://doi.org/10.1016/j.jpha.2015.11.005

Banani H, Spadaro D, Zhang D, Matic S, Garibaldi A, Gullino ML (2015) Postharvest application of a novel chitinase cloned from Metschnikowia fructicola and over expressed in Pichia pastoris to control brown rot of peaches. Int $\mathrm{J}$ Food Microbiol 199:54-61. https://doi.org/10.1016/j. ijfoodmicro.2015.01.002

Barbosa C, Lage P, Esteves M, Chambel L, Mendes-Faia A, Mendes-Ferreira A (2018) Molecular and phenotypic characterization of Metschnikowia pulcherrima strains from Douro Wine region. Fermentation 4(1):8. https://doi. org/10.3390/fermentation4010008

Castoria R, Caputo L, De Curtis F, De Cicco V (2003) Resistance of postharvest biocontrol yeasts to oxidative stress: a possible new mechanism of action. Phytopathology 93(5):564-572. https://doi.org/10.1094/PHYTO.2003.93. 5.564

Chi M, Li G, Liu Y, Liu G, Li M, Zhang X, Sun Z, Sui Y, Liu J (2015) Increase in antioxidant enzyme activity, stress tolerance and biocontrol efficacy of Pichia kudriavzevii with the transition from a yeast-like to biofilm morphology. Biol Control 90:113-119. https://doi.org/10.1016/j.biocontrol. 2015.06.006

Commission Implementing Regulation (EU) (2018/1915) approving the active substance Metschnikowia fructicola strain NRRL Y-27328 in accordance with Regulation (EC) No $1107 / 2009$ of the European Parliament and of the Council concerning the placing of plant protection products on the market, and amending the Annex to Commission Implementing Regulation (EU) No 540/2011 
Durrens P, Klopp C, Biteau N, Fitton-Ouhabi V, Dementhon K, Accoceberry I, Sherman DJ, Noëlb T (2017) Genome sequence of the yeast Clavispora lusitaniae type strain CBS 6936. Genome Announc 5:e00724-17. https://doi.org/ 10.1128/genomeA.00724-17

El-Tarabily KA, Sivasithamparam K (2006) Potential of yeasts as biocontrol agents of soil-borne fungal plant pathogens and as plant growth promoters. Mycoscience 47:25-35. https://doi.org/10.1007/s10267-005-0268-2

European Food Safety Authority-EFSA (2018) The 2016 European Union report on pesticide residues in food. EFSA J 16(7):5348

Fia G, Giovani G, Rosi I (2005) Study of $\beta$-glucosidase production by wine-related yeasts during alcoholic fermentation. A new rapid fluorimetric method to determine enzymatic activity. J Appl Microbiol 99(3):509-517. https://doi.org/10.1111/j.1365-2672.2005.02657.x

Fortuniak W, Pospiech P, Mizerska U, Chojnowski J, Slomkowski S, Nyczyk-Malinowska A, Wojteczko A, WislaWalsh E, Hasik M (2018) Generation of meso- and microporous structures by pyrolysis of polysiloxane microspheres and by HF etching of SiOC microspheres. Ceram Int 44(1):374-383. https://doi.org/10.1016/j. ceramint.2017.09.184

Glare TR, Gwynn RL, Moran-Diez ME (2016) Development of biopesticides and future opportunities. In: Walter JM (ed) Methods in molecular biology. Springer, Berlin, pp 211-221

Hu H, Wisniewski ME, Abdelfattah A, Zheng X (2017) Biocontrol activity of a cold adapted yeast from Tibet against gray mold in cherry tomato and its action mechanism. Extremophiles 21:789-803. https://doi.org/10.1007/ s00792-017-0943-1

James SA, O'Kelly MJT, Carter DM, Davey RP, van Oudenaarden A, Roberts IN (2009) Repetitive sequence variation and dynamics in the ribosomal DNA array of Saccharomyces cerevisiae as revealed by whole-genome resequencing. Genome Res 19:626-635. https://doi.org/10. 1101/gr.084517.108

James SA, Barriga EJC, Barahona PP, Cross K, Bond CJ, Roberts IN (2013) Candida ecuadorensis sp. nov., an ascomycetous yeast species found in two separate regions of Ecuador. Int J Syst Evol Microbiol 63(1):393-397. https://doi.org/10.1099/ijs.0.047555-0

James SA, Barriga EJC, Barahona PP, Harrington TC, Lee CF, Bond CJ, Roberts IN (2014) Wickerhamomyces arborarius f.a., sp. nov., an ascomycetous yeast species found in arboreal habitats on three different continents. Int J Syst Evol Microbiol 64(3):1054-1061. https://doi.org/10.1099/ ijs.0.059162-0

James SA, Barriga EJC, Barahona PP, Nueno-Palop C, Cross K, Bond CJ, Roberts IN (2015) Kazachstania yasuniensis sp. nov., an ascomycetous yeast species found in mainland Ecuador and on the Galápagos. Int J Syst Evol Microbiol 65:1304-1309. https://doi.org/10.1099/ijs.0.000102

Jensen DF, Karlsson M, Sarrocco S, Vannacci G (2016) Biological control using microorganisms as an alternative to disease resistance. In: Collinge DB (ed) Plant pathogen resistance biotechnology. Wiley, New York, pp 341-363

Kang YM, Choi JE, Komakech R, Park JH, Kim DW, Cho KM, Kang SM, Choi SH, Song KC, Ryu CM, Lee KC, Lee JS
(2017) Characterization of a novel yeast species Metschnikowia persimmonesis KCTC 12991BP (KIOM G15050 type strain) isolated from a medicinal plant, Korean persimmon calyx (Diospyros kaki Thumb). AMB Express 7:199. https://doi.org/10.1186/s13568-017-0503-1

Kántor A, Hutková J, Petrová J, Hleba L, Kačániová M (2015) Antimicrobial activity of pulcherrimin pigment produced by Metschnikowia pulcherrima against various yeast species. J Microbiol Biotechnol Food Sci 5(3):282-285. https://doi.org/10.15414/jmbfs.2015/16.5.3.282-285

Koike ST, Bolda M (2016) Botrytis fruit rot of strawberry: production guideline. California strawberry commercial production guideline. https://ucanr.edu/blogs/ strawberries_caneberries/blogfiles/37846.pdf. Accessed 24 Oct 2018

Krasowska A, Sigler K (2014) How microorganisms use hydrophobicity and what does this mean for human needs? Front Cell Infect Microbiol 4:112. https://doi.org/10.3389/ fcimb.2014.00112

Kregiel D (2013a) Adhesion of Aeromonas hydrophila to glass surfaces modified with organosilanes. Food Technol Biotechnol 51(3):345-351

Kregiel D (2013b) Attachment of Asaia lannensis to materials commonly used in beverage industry. Food Control 32(2):537-542. https://doi.org/10.1016/j.foodcont.2013. 01.037

Kregiel D, James SA, Rygala A, Berlowska J, Antolak H, Pawlikowska E (2018) Consortia formed by yeasts and acetic acid bacteria Asaia spp. in soft drinks. Antonie Leeuw J Microb 111(3):373-383. https://doi.org/10.1007/ s10482-017-0959-7

Kurtzman CP (2011) Phylogeny of the ascomycetous yeasts and the renaming of Pichia anomala to Wickerhamomyces anomalus. Antonie Van Leeuwenhoek 99(1):13-23

Kurtzman CP, Robnett CJ (1998) Identification and phylogeny of ascomycetous yeasts from analysis of nuclear large subunit (26S) ribosomal DNA partial sequences. Antonie Leeuw J Microb 73(4):331-371

Kurtzman CP, Robnett CJ, Basehoar E, Ward TJ (2018) Four new species of Metschnikowia and the transfer of seven Candida species to Metschnikowia and Clavispora as new combinations. Antonie Leeuw J Microb 111(11):1-19. https://doi.org/10.1007/s10482-018-1095-8

Kwasiborski A, Bajji M, Renaut J, Delaplace P, Jijakli MH (2014) Dentification of metabolic pathways expressed by Pichia anomala Kh6 in the presence of the pathogen Botrytis cinerea on apple: new possible targets for biocontrol improvement. PLoS ONE 9(3):e91434. https://doi. org/10.1371/journal.pone.0091434

Lachance MA, Fedor AN (2014) Catching speciation in the act: Metschnikowia bowlesiae sp. nov., a yeast species found in nitidulid beetles of Hawaii and Belize. Antonie Van Leeuwenhoek 105(3):541-550. https://doi.org/10.1007/ s10482-013-0106-Z

Lachance MA, Hurtado E, Hsiang T (2016) A stable phylogeny of the large-spored Metschnikowia clade. Yeast 33(7):261-275. https://doi.org/10.1002/yea.3163

Le Cointe R, Simon TE, Delarue P, Hervé M, Leclerc M, Poggi S (2016) Reducing the use of pesticides with site-specific application: the chemical control of Rhizoctonia solani as a case of study for the management of soil-borne diseases. 
PLoS ONE 11(9):e0163221. https://doi.org/10.1371/ journal.pone.0163221

Li C, Zhang H, Yang Q, Komla MG, Zhang X, Zhu S (2014) Ascorbic acid enhances oxidative stress tolerance and biological control efficacy of Pichia caribbica against postharvest blue mold decay of apples. J Agric Food Chem 62(30):7612-7621. https://doi.org/10.1021/jf501984n

Liu J, Wisniewski M, Droby S, Tian S, Hershkovitz V, Tworkoski T (2011) Effect of heat shock treatment on stress tolerance and biocontrol efficacy of Metschnikowia fructicola. FEMS Microbiol Ecol 76(1):145-155. https://doi. org/10.1111/j.1574-6941.2010.01037.x

Liu J, Wisniewski M, Droby S, Norelli J, Hershkovitz V, Tian S, Farrell R (2012) Increase in antioxidant gene transcripts, stress tolerance and biocontrol efficacy of Candida oleophila following sublethal oxidative stress exposure. FEMS Microbiol Ecol 80(3):578-590. https://doi.org/10.1111/j. 1574-6941.2012.01324.x

Liu J, Sui Y, Wisniewski M, Droby S, Liu Y (2013) Review: utilization of antagonistic yeasts to manage postharvest fungal diseases of fruit. Int $\mathrm{J}$ Food Microbiol 167(2):153-160. https://doi.org/10.1016/j.ijfoodmicro. 2013.09.004

Liu P, Fang J, Chen K, Long C, Cheng Y (2014) Phenylethanol promotes adhesion and biofilm formation of the antagonistic yeast Kloeckera apiculata for the control of blue mold on citrus. FEMS Yeast Res 14(4):536-546. https:// doi.org/10.1111/1567-1364.12139

Liu Y, Wang W, Zhou Y, Yaoa S, Denga L, Zeng K (2017) Isolation, identification and in vitro screening of Chongqing orangery yeasts for the biocontrol of Penicillium digitatum on citrus fruit. Biol Control 110:18-24. https://doi. org/10.1016/j.biocontrol.2017.04.002

Mills DA, Johannsen EA, Cocolin L (2002) Yeast diversity and persistence in botrytis-affected wine fermentations. Appl Environ Microbiol 68(10):4884-4893. https://doi.org/10. 1128/AEM.68.10.4884-4893

Nowak A, Czyzowska A, Efenberger-Szmechtyk M, Krala L (2016) Polyphenolic extracts of cherry (Prunus cerasus L.) and blackcurrant (Ribes nigrum L.) leaves as natural preservatives in meat products. Food Microbiol 59:142-149. https://doi.org/10.1016/j.fm.2016.06.004

O'Donnell K (1993) Fusarium and its near relatives. In: Reynolds DR, Taylor JW (eds) The fungal holomorph: mitotic, meiotic and pleomorphic speciation in fungal systematics. CAB International, Wallingford, pp 225-233

Oro L, Ciani M, Comitini F (2014) Antimicrobial activity of Metschnikowia pulcherrima on wine yeasts. J Appl Microbiol 116(5):1209-1217. https://doi.org/10.1111/jam. 12446

Parafati L, Vitale A, Restuccia C, Cirvilleri G (2015) Biocontrol ability and action mechanism of food-isolated yeast strains against Botrytis cinerea causing post-harvest bunch rot of table grape. Food Microbiol 47:85-92. https://doi.org/10. 1016/j.fm.2014.11.013

Perpetuini G, Tittarelli F, Mattarelli P, Modesto M, Cilli E, Suzzi G, Tofalo R (2018) Intraspecies polymorphisms of Kluyveromyces marxianus strains from Yaghnob valley. FEMS Microbiol Lett. https://doi.org/10.1093/femsle/ fny028
Pretscher J, Fischkal T, Branscheidt S, Jäger L, Kahl S, Schlander M, Thines E, Claus H (2018) Yeasts from different habitats and their potential as biocontrol agents. Fermentation 4:31. https://doi.org/10.3390/fermentation4020031

Regnault-Roger C (2012) Trends for commercialization of biocontrol agent (biopesticide) products. In: Mérillon J, Ramawat K (eds) Plant defence: biological control. Progress in biological control, vol 12. Springer, Dordrecht, pp 139-160

Rodríguez PFP, Arévalo-Villena M, Rosa IZ, Pérez AB (2018) Selection of potential non-Sacharomyces probiotic yeasts from food origin by a step-by-step approach. Food Res Int 112:143-151. https://doi.org/10.1016/j.foodres.2018.06. 008

Samsidar A, Siddiquee S, Shaaranib SM (2018) A review of extraction, analytical and advanced methods for determination of pesticides in environment and foodstuffs. Trends Food Sci Technol 71:188-201. https://doi.org/10.1016/j. tifs.2017.11.011

Sangorrín MP, Lopes CA, Vero S, Wisniewski M (2014) Coldadapted yeasts as biocontrol agents: biodiversity, adaptation strategies and biocontrol potential. In: Buzzini P, Margesin R (eds) Cold-adapted yeasts. Springer, Berlin, pp 441-464

Saravanakumar D, Ciavorella A, Spadaro D, Garibaldi A, Gullino ML (2008) Metschnikowia pulcherrima strain MACH1 outcompetes Botrytis cinerea, Alternaria alternata and Penicillium expansum in apples through iron depletion. Postharvest Biol Technol 49(1):121-128. https://doi.org/10.1016/j.postharvbio.2007.11.006

Sarrocco S, Vannacci G (2018) Preharvest application of beneficial fungi as a strategy to prevent postharvest mycotoxin contamination: a review. Crop Prot 110:160-170. https:// doi.org/10.1016/j.cropro.2017.11.013

Savary S, Ficke A, Aubertot JN, Hollier C (2012) Crop losses due to diseases and their implications for global food production losses and food security. Food Secur 4(4):519-537. https://doi.org/10.1007/s12571-012-0200-5

Sipiczki M (2006) Metschnikowia strains isolated from botrytized grapes antagonize fungal and bacterial growth by iron depletion. Appl Environ Microbiol 72(10):6716-6724. https://doi.org/10.1128/AEM.01275-06

Sipiczki M, Pfliegler WP, Holb IJ (2013) Metschnikowia species share a pool of diverse rRNA genes differing in regions that determine hairpin-loop structures and evolve by reticulation. PLoS ONE 8(6):e67384. https://doi.org/10.1371/ journal.pone.0067384

Sipiczki M, Horvath E, Pfliegler WP (2018) Birth-and-death evolution and reticulation of ITS segments of Metschnikowia andauensis and Metschnikowia fructicola rDNA repeats. Front Microbiol 9:1193. https://doi.org/10.3389/ fmicb.2018.01193

Sisti M, Savini V (2014) Antifungal properties of the human Metschnikowia strain IHEM 25107. Folia Microbiol 59(3):263-266. https://doi.org/10.1007/s12223-013-02902

Spadaro D, Ciavorella AA, Lopez-Reyes JG, Garibaldi A, Gullino ML (2010) Effect of culture age, protectants, and initial cell concentration on viability of freeze-dried cells of Metschnikowia pulcherrima. Can J Microbiol 56(10):809-815. https://doi.org/10.1139/w10-068 
Staniszewska M, Bondaryk M, Swoboda-Kopec E, Siennicka K, Sygitowicz G, Kurzatkowski W (2013) Candida albicans morphologies revealed by scanning electron microscopy analysis. Braz J Microbiol 44(3):813-821. https://doi.org/ $10.1590 /$ S1517-83822013005000056

Sui Y, Wisniewski M, Droby S, Liu J (2015) Responses of yeast biocontrol agents to environmental stress. Appl Environ Microbiol 81(9):2968-2975. https://doi.org/10.1128/ AEM.04203-14

Türkel S, Ener B (2009) Isolation and characterization of new Metschnikowia pulcherrima strains as producers of the antimicrobial pigment pulcherrimin. Z Naturforsch $\mathrm{C}$ 64(5-6):405-410

Türkel S, Korukluoglu M, Yavuz M (2014) Biocontrol activity of the local strain of Metschnikowia pulcherrima on different postharvest pathogens. Biotechnol Res Int. https:// doi.org/10.1155/2014/397167

Wang Y, He S, Xia J, Yu T, Zheng X (2014) Acid adaptation and biocontrol efficacy of antagonistic marine yeast Rhodosporidium paludigenum. Ann Microbiol 64(2):503-508. https://doi.org/10.1007/s13213-013-0681-2
Wisniewski M, Macarisin D, Droby S (2010) Erkan M, Aksoy U (eds) Proceedings of 6th international postharvest symposium. Acta Hort. 877, ISHS 2010, pp 1577-1582

Xue ML, Zhang LQ, Wang QM, Zhang JS, Bai FY (2006) Metschnikowia sinensis sp. nov., Metschnikowia zizyphicola sp. nov. and Metschnikowia shanxiensis sp. nov., novel yeast species from jujube fruit. Int J Syst Evol Microbiol 56(9):2245-2250. https://doi.org/10.1099/ijs.0. 64391-0

Zhang Q, Zhao L, Li Z, Li C, Li B, Gu X, Zhang X, Zhang H (2019) Screening and identification of an antagonistic yeast controlling postharvest blue mold decay of pears and the possible mechanisms involved. Biol Control 133:26-33. https://doi.org/10.1016/j.biocontrol.2019.03.002

Publisher's Note Springer Nature remains neutral with regard to jurisdictional claims in published maps and institutional affiliations. 